\title{
Magnetic properties of ferritin and akaganeite nanoparticles in aqueous suspension
}

\author{
Marceli Koralewski • Mikołaj Pochylski • \\ Jacek Gierszewski
}

Received: 14 December 2012/ Accepted: 26 July 2013/Published online: 14 August 2013

(C) The Author(s) 2013. This article is published with open access at Springerlink.com

\begin{abstract}
We have studied the magnetically induced optical birefringence $\Delta n$ of horse spleen ferritin (HSF) and aqueous suspensions of several different-sized iron oxyhydroxide nanoparticles coated with different polysaccharides mimicking ferritin. The structure and dimensions of the akaganeite mineral core were characterized by XRD and TEM, respectively. The stability of the suspensions in the measurement temperature range from 278 to $358 \mathrm{~K}$ was confirmed by UV-Vis absorption spectroscopy. The values of optical polarizability anisotropy $\Delta \alpha$, magnetic susceptibility anisotropy $\Delta \chi$, and permanent magnetic dipole moment $\mu_{\mathrm{m}}$ of the akaganeite nanoparticles have been estimated on the basis of the temperature dependence of the Cotton-Mouton ( $\mathrm{C}-\mathrm{M})$ constant. The magnetic birefringence of $\mathrm{Fe}$-sucrose has been described tentatively by different types of Langevin function allowing another estimation of $\Delta \chi$ and $\mu_{\mathrm{m}}$. The obtained permanent magnetic dipole moment $\mu_{\mathrm{m}}$ of the studied akaganeite nanoparticles proves small and comparable to that of HSF. The value of $\mu_{\mathrm{m}}$ is found to increase with decreasing nanoparticle diameter. Observed in a range spanning more than five orders of magnitude, the linear relation between the $\mathrm{C}-\mathrm{M}$ constant and the iron concentration provides a basis for possible analytical application of the $\mathrm{C}-\mathrm{M}$ effect in biomedicine. The
\end{abstract}

M. Koralewski $(\square) \cdot$ M. Pochylski · J. Gierszewski Optics Laboratory, Faculty of Physics, Adam Mickiewicz University, Umultowska 85, 61-614 Poznan, Poland e-mail: koral@amu.edu.pl established relation between the $\mathrm{C}-\mathrm{M}$ constant and the nanoparticle diameter confirms that the dominant contribution to the measured magnetic birefringence comes from the magnetic susceptibility anisotropy $\Delta \chi$. A comparison of the $\mathrm{C}-\mathrm{M}$ constants of the studied akaganeite nanoparticles with the data obtained for HSF provides evidence that the ferritin core behaves as a non-Euclidian solid.

Keywords Magnetic birefringence $\cdot$ CottonMouton effect · Akaganeite $\cdot$ Ferritin $\cdot$ Magnetic susceptibility anisotropy $\cdot$ Langevin function

\section{Introduction}

Essential for life processes, iron plays a very important role in living organisms of all species (Lindley 1996). It is stored by animals and plants, as well as bacteria, inside the protein ferritin (Harrison and Arosio 1996). Malfunction of the iron-storing mechanism of ferritin leads to serious, mostly blood diseases, the treatment of which requires the intravenous application of an iron-containing agent. Different polysaccharide iron complexes (PICs) are pharmaceutically important substitutes for ferritin, used as hematinics for the treatment of anemia (London 2004; Funk et al. 2001). Also, PICs are often used as model systems in physicochemical studies of ferritin. Although the mineral cores of PICs and ferritin have different unit 
cells, both have $\mathrm{Fe}^{3+}$ ions octahedrally coordinated by oxygen. Aside from purely pharmaceutical applications, the increasing interest in iron oxyhydroxide particles of desired size and chemical properties is also stimulated by their potential technological applications, especially as a low-cost adsorbing agent (Ibrahim et al. 1994; Kolbe et al. 2011; Xu et al. 2012).

A PIC system is an aqueous colloidal suspension composed of an iron oxyhydroxide-based core of a diameter of a few nanometers surrounded by a polysaccharide shell a few nanometer thick (London 2004; Funk et al. 2001). Besides the well-known iron dextran (London 2004; Lawrence 1998), commonly used as a drug and in research (Kilcone and Gorisek 1998), the commercially available PICs include, among others, Venofer ${ }^{\circledR}$, a complex of polynuclear iron(III) oxyhydroxide in sucrose (Venofer ${ }^{\circledR}$ 2011), Dexferrum $^{\circledR}$, a complex of iron oxyhydroxide stabilized by dextran (Dexferrum ${ }^{\circledR}$ 2010), or Ferrum Lek, iron oxyhydroxide stabilized by polymaltose (Ferrum LEK $^{\circledR}$ 2010). Although the clinical applications of PICs are well documented in the literature (see, e.g., Venofer $^{\circledR}$ 2009), only a few studies focus on the physicochemical properties of these compounds (Funk et al. 2001; Gutierrez et al. 2005; Kudasheva et al. 2004; Knight et al. 1999). Polysaccharide iron complexes have been characterized by X-ray diffraction (XRD), iron-57 Mossbauer spectroscopy, transmission electron microscopy (TEM), atomic force microscopy (AFM), and other techniques (Ibrahim et al. 1994). Some magnetic properties were found in magnetization and susceptibility measurements (Gutierrez et al. 2005). In spite of the considerable experimental effort many properties of PIC systems remain to be explored and specified.

There is some controversy about the mineral constitution of the iron core. The X-ray diffraction data show that the structure of the core is the most consistent with the akaganeite polymorph $\beta$-FeOOH (Funk et al. 2001; Kudasheva et al. 2004; Knight et al. 1999; Kilcoyne and Lawrence 1999). However, some authors claim that the core has rather a 2-line ferrihydrite structure (Gutierrez et al. 2005). Others suppose (Coe et al. 1995a) an intermediate structure between that of akaganeite and ferrihydrite, which can appear to closely resemble both, depending on the technique used for structure probing. Most of the studies of PICs performed so far used freeze-dried samples in low-temperature conditions (Coe et al. 1995a, b; Oshtrakh et al. 2006). Studies of the liquid state of PIC suspensions at physiological temperature $(310 \mathrm{~K})$ or above room temperature $(\mathrm{RT})$ are rare and mostly obscure. We have recently published preliminary data on the magnetic properties of the liquid hematinic iron sucrose aqueous suspension (Koralewski et al. 2011a). We have shown that magnetooptical effects can be of much use for the discrimination of the valency of iron and the description of magnetic characteristics of ferrofluids (Koralewski et al. 2011b, 2012a, b). The magnetic characteristics of ferritin and PIC compounds are of key interest for noninvasive assessment of iron in human body, e.g. by magnetic resonance imaging (MRI) or susceptometry, in the frame of emerging techniques in medical practice (Schenck and Zimmerman 2004; Carneiro et al. 2005).

In this study we present the magnetically-induced linear optical birefringence and its temperature dependence in several commercial hematinics in the form of aqueous suspension of iron oxyhydroxide nanoparticles with different core sizes. We use these data for determining the magnetic dipolar properties of the nanoparticles. The results obtained are compared with those of similar measurements performed for horse spleen ferritin (HSF), and discussed in the light of earlier investigations of similar nanoscale systems. The discussion of the results is supported by additional $\mathrm{XRD}$, TEM, VSM, refractive index, and UV-Vis absorption spectrum measurements.

\section{Experimental}

The iron dextran (Sigma) and parenteral iron formulations used in this study were iron oxyhydroxide polysaccharide aqueous suspensions specified in Table 1. Horse spleen ferritin was used as a natural biogenic ferritin. Several different lots of holoferritin and apoferritin were purchased from Sigma and were used without further processing. Pure dextran (5 kDa) was obtained from Pharmacosmos (Denmark). Fi$\operatorname{coll}^{\circledR}-70$, a synthetic polymer of sucrose, and a maltose solution were purchased from Fluka.

The iron content in the mother liquors, i.e., asreceived original iron polysaccharide liquid suspensions, and in HSF was measured by inductively coupled plasma (ICP) optical emission spectrometry (OES) with a VISTA-MPX (Varian) spectrometer. 
Table 1 Selected physicochemical properties of the studied iron oxyhydroxide polysaccharide aqueous suspensions, with error in parentheses

\begin{tabular}{|c|c|c|c|c|}
\hline $\begin{array}{l}\text { Property } \\
\text { Trade name } \\
\text { Supplier }\end{array}$ & $\begin{array}{l}\text { Fe-sucrose } \\
\text { Venofer }^{\circledR} \\
\text { Lek }\end{array}$ & $\begin{array}{l}\text { Fe-polymaltose } \\
\text { Ferrum Lek }{ }^{\circledR} \\
\text { Lek }\end{array}$ & $\begin{array}{l}\text { Fe-dextran } \\
\text { Dexferrum }^{\circledR} \\
\text { American Regent }\end{array}$ & $\begin{array}{l}\text { Fe-dextran }(\mathrm{S}) \\
\text { Iron dextran } \\
\text { Sigma-Aldrich }\end{array}$ \\
\hline Core & Akaganeite & Akaganeite & Akaganeite & Akaganeite \\
\hline Carrier & Water & Water & Water & Water \\
\hline Shell & Polysucrose & Polymaltose & Dextran & Dextran \\
\hline Fe-content $(\mathrm{g} / \mathrm{L})^{\mathrm{a}}$ & $20(1.4)$ & $50(3.5)$ & $50(3.5)$ & $100(7)$ \\
\hline Density $\left(10^{3} \mathrm{~kg} / \mathrm{m}^{3}\right)^{\mathrm{a}}$ & 1.1576 & 1.0863 & 1.1483 & 1.1789 \\
\hline Refractive index ${ }^{\mathrm{b}}$ & 1.3341 & 1.3317 & 1.3321 & 1.3321 \\
\hline \multicolumn{5}{|l|}{ Core diameter (nm) } \\
\hline $\mathrm{XRD}^{\mathrm{c}}$ & $\sim 3.8(0.7)$ & 6.5 & 5.6 & 5.6 \\
\hline TEM & $\sim 3(0.5)$ & 6 & 4.5 & $5 \times 16$ \\
\hline
\end{tabular}

${ }^{a}$ Mother liquor/aqueous suspension at RT

b $\lambda=632.8 \mathrm{~nm}, \mathrm{RT}, c^{\mathrm{Fe}}=1 \mathrm{~g} / \mathrm{L}$

c Estimated for (211) diffraction peak

The iron content in the sample was as claimed by the supplier (see Table 1) within the experimental error (less than $7 \%$ ). For optical studies the initial suspension was further diluted with triple-distilled demineralized water.

Room temperature X-ray diffraction (XRD) measurements were performed using $\mathrm{CuK} \alpha$ $(\lambda=0.154056 \mathrm{~nm})$ radiation with a D8 Advance (Bruker) diffractometer. The sample, i.e., the mother liquor suspension, was held in a glass capillary during the experiment. Transmission electron microscopy (TEM) analysis was performed with a JEM-1200 EX II (JEOL) microscope operated at $80 \mathrm{kV}$. Magnetization measurements were carried out at room temperature with a home-made vibrating sample magnetometer (VSM) (Koralewski et al. 2012a).

The optical birefringence was measured by means of a home-built polarimeter described in detail by Koralewski et al. (2011a). The instrument allows precise measurements of the angle $\theta$ of rotation of the polarization plane for light passing through a sample in a magnetic field in the Voigt configuration. The sample was held in a jacketed cylindrical glass cell with a pathlength ranging from 2 to $100 \mathrm{~mm}$, depending on the iron concentration in the sample. A Haake programmable refrigerant circulator (Thermo-Fisher) was used for temperature stabilization in the temperature range from 278 to $358 \mathrm{~K}$ with an accuracy better than $0.1 \mathrm{~K}$. The light beam from a $\mathrm{He}-\mathrm{Ne}$ laser $(\lambda=632.8 \mathrm{~nm})$ was used.
The angle $\theta$ of rotation of incident polarized light is proportional to the birefringence $\Delta n$ of the sample by the well-known relation:

$\theta=\frac{\pi L}{\lambda} \Delta n$,

where $L$ denotes the length of the cell and $\lambda$ the wavelength of the light used. The accuracy of the angle estimation was better than $0.001^{\circ}$. This angular precision, together with utilization of sufficiently long sample cell, allows the magnetic birefringence $\Delta n$ to be measured with accuracy better than $10^{-9}$. The maximal feasible optical path, and so the precision of $\Delta n$, was limited by the transparency of studied fluid (different for different concentrations of magnetic nanoparticles). For each sample examined many trials were performed to find optimal cell length minimizing the error in the Cotton-Mouton constant, $C^{\mathrm{CM}}$. Depending on the range of the value of $C^{\mathrm{CM}}$ and concentration of iron in fluid under examination we were able to determine the $C^{\mathrm{CM}}$ with relative error from 0.05 to $10 \%$. In order to conduct an automated experiment the current supply, the gaussmeter, the refrigerant circulator, the analyzer rotary stage and the photomultiplier were all interfaced to a PC computer. A program written in LabVIEW $^{\circledR}$ was used for synchronizing the measurement sequence and for data collection.

The dispersion and the temperature dependence of the light refractive index $n$ of diluted liquid iron 
polysaccharide suspensions were measured with a Pulfrich refractometer PR2 (Zeiss) equipped with a thermostatable prism allowing measurements of $n$ in the temperature range from 278 to $318 \mathrm{~K}$. The refractive index was measured with accuracy \pm 0.0001 . The absorption spectra were measured with a computer-aided Specord M40 (Zeiss) spectrophotometer in the temperature range from 278 to $363 \mathrm{~K}$ using a jacketed quartz cell with a $10 \mathrm{~mm}$ pathlength. An MK 70 (Zeiss) thermostat with temperature control $\pm 0.1 \mathrm{~K}$ was used in both cases. The estimated error for molar extinction coefficient is below $0.1 \%$. The density was measured using a DMA 38 (Anton Paar) density meter in the temperature range from 278 to $318 \mathrm{~K}$ with accuracy $\pm 0.0001 \mathrm{~g} / \mathrm{cm}^{3}$.

\section{Theoretical background}

Since Majorana (1902) and Cotton and Mouton's (1907) discovery magnetic field is known to induce molecular order via dipolar alignment. Hence, optical birefringence can occur in suspensions of anisotropic, anisometric, and diamagnetic particles. There are two types of origin of magnetic dipoles. The permanent magnetic dipole moment $\mu_{\mathrm{m}}$ is inherent and characteristic of the molecular structure. A magnetic dipole moment can be also induced by a magnetic field. In the latter case the value of the magnetic dipole moment is related to the magnetic susceptibility and its anisotropy $\Delta \chi$ in the material.

The analysis of the static optical birefringence of a dilute suspension of axially symmetrical particles follows the description proposed by (Peterlin and Stuart 1939), developed by O'Konski et al. (1952) and discussed by other authors (Wilson et al. 1998; Hassamony et al. 1989). In this approach, the optical birefringence induced by a continuous magnetic field of magnitude $B$ is given by (in SI units):

$\Delta n=\Delta n_{\mathrm{s}} F(p, q)=\frac{\rho^{N} \Delta \alpha}{2 n \varepsilon_{0}} F(p, q)$,

where $\Delta n_{\mathrm{s}}$ is the saturation magnetic birefringence described by the anisotropy $\Delta \alpha$ of volume optical polarizability, $\rho^{\mathrm{N}}$ is the volume concentration (particle number density), $n$ is the refractive index of the solution, $\varepsilon_{0}$ denotes the permittivity of free space, and $F(p, q)$ is a statistical particle orientation function. In the case of magnetic birefringence the parameters of $F(p, q)$ correspond to the energy of interaction of the magnetic field with both the permanent and induced magnetic dipole moments. In general, in the low magnetic field strength limit, after O'Konski et al. (1952) the orientation function $F(p, q)$ is given by:

$F=\left(p^{2}+2 q\right) / 15$,

where $p=\mu_{\mathrm{m}} B / k T, q=\Delta \chi B^{2} /\left(2 \mu_{0} k T\right), \quad \mu_{0}$ is the permeability of free space, $k$ is the Boltzmann constant, and $T$ stands for the absolute temperature.

Measurements in the range referred to as the lowfield region, in which the birefringence changes as the square of the magnetic field $B$, allow direct calculation of the Cotton-Mouton constant $C^{\mathrm{CM}}$ from the relation:

$\Delta n=C^{C M} \lambda B^{2}$.

Taking into account Eqs. (2), (3), and (4), the CottonMouton constant can be written as:

$C^{\mathrm{CM}}=\frac{\rho^{N} \Delta \alpha}{30 n \varepsilon_{0} \lambda}\left\{\frac{\Delta \chi}{\mu_{0} k T}+\left(\frac{\mu_{\mathrm{m}}}{k T}\right)^{2}\right\}$.

As implied by Eq. (5), the values of $\Delta \chi$ and $\mu_{\mathrm{m}}$ can be determined from the temperature dependence of the Cotton-Mouton constant only if the value of $\Delta n_{\mathrm{s}}$ or $\Delta \alpha$ is known. Although $\Delta \alpha$ can be measured in different experiments, its value can also be estimated from the saturation of the magnetic birefringence $\Delta n_{\mathrm{s}}$ (observed at high magnetic fields) and the refractive index (see Eq. (2)). When the magnetic field is too low for full magnetic birefringence saturation to occur, an extrapolation of $\Delta n$ to the high-field limit allows to estimate $\Delta n_{\mathrm{s}}$. In this case the saturation magnetic birefringence can be obtained from the $\Delta n$ versus $1 / B^{2}$ relation by graphical extrapolation.

The temperature dependence of the Cotton-Mouton constant can be linearized by plotting the product $G T C^{\mathrm{CM}}$ versus $1 / T$. The parameter $G$ relates to $\Delta \alpha$ as $G=30 n k \varepsilon_{0} \lambda / \rho^{\mathrm{N}} \Delta \alpha(T)=15 k \lambda / \Delta n_{\mathrm{s}}(T)$ and can be assumed either constant (in which case a $T C^{\mathrm{CM}}$ versus $1 / T$ plot will suffice) or temperature-dependent (through $\Delta n_{\mathrm{s}}$ ). The approaches based on these two assumptions, with $\Delta n_{\mathrm{s}}$ temperature-independent or temperature-dependent, will be henceforth referred to as the first and second methods of linearization, respectively. In each case the values of $\Delta \chi$ and $\mu_{\mathrm{m}}$ of the particle can be calculated from the intercept and the slope of the linearized dependence. It needs to be 
stressed that both values strongly depend on the precision of estimation of $\Delta \alpha\left(\Delta n_{\mathrm{s}}\right)$.

In the case of complete (or nearly complete) ordering of the magnetic moments, when saturation of magnetic birefringence occurs, the phenomenon can be described by a second-order Langevin function $L_{2}$ as the statistical orientation function figuring in Eq. (2) (Hassamony et al. 1989; Scholten 1975; Neitzel and Barner 1977). Taking into account only the contribution from the permanent magnetic moments to the magnetic orientation effects, the value of birefringence can be calculated from:

$\Delta n=\Delta n_{\mathrm{s}} L_{2}(p)=\frac{\rho^{N} \Delta \alpha}{2 n \varepsilon_{0}} L_{2}(p)$,

where $L_{2}(p)=1-3 L_{1}(p) / p$, and $L_{1}(p)$ is the usual firstorder Langevin function.

The value of $\mu_{\mathrm{m}}$ can be obtained directly by fitting the Eq. (6) to the experimental static birefringence measured as a function of $B$. The value of magnetic field required to saturate the Langevin function also provides information on the average magnetic moment, since the field decreases with increasing magnetic moment.

The description of orientation phenomena can be generalized by allowing for contributions from both permanent and induced magnetic moments. As shown by Kielich (1970) in such case the $L_{2}$ term depends on both $p$ and $q$ :

$\Delta n=\Delta n_{\mathrm{s}} L_{2}(p, \pm q)$.

The sign of $q$ refers to positive or negative anisotropy of magnetic susceptibility. Although the integral in the expression for $L_{2}(p, q)$ cannot be solved analytically (Kielich 1970; Scholten 1975), numerical procedures allow to obtain the values of $\mu_{\mathrm{m}}$ and $\Delta \chi$ by fitting the experimental $\Delta n(B)$ dependence to the Eq. (6a).

If the spherical shape of the particles can be assumed the value of permanent magnetic moment is related to the diameter $D$ of each particle and its saturation magnetization $M_{\mathrm{s}}$ by the formula:

$\mu_{\mathrm{m}}=M_{\mathrm{s}} \pi D^{3} / 6$.

If $M_{\mathrm{S}}$ is known from independent measurements, Eq. (7) can be used for estimating the particle diameter $D$ (and vice versa).
When the system is a polydisperse suspension Eq. (6) or (6a) need to be rewritten to take into account the particle size distribution:

$\Delta n=\Delta n_{\mathrm{s}} \frac{\int L_{2} P(D) D^{3} d D}{\int P(D) D^{3} d D}$,

where $L_{2}$ can be $L_{2}(p)$ or $L_{2}(p, \pm q)$, and $\mathrm{P}(D)$ is the most commonly used log-normal size distribution function defined as (Popplewell and Sakhnini 1995):

$P(D)=\frac{1}{\sqrt{2 \pi} s D} \exp \left[-\frac{\ln ^{2}\left(D / D_{0}\right)}{2 s^{2}}\right]$,

where $D_{0}$ and $s$ are parameters of the distribution function $P(D)$, related to the average diameter $\langle D\rangle$ and the standard deviation $\sigma$ by the formulas (Rasa 2000):

$$
\begin{aligned}
& \langle D\rangle=D_{0} \exp \left(s^{2} / 2\right) \text { and } \\
& \sigma=D_{0} \exp \left(s^{2} / 2\right)\left(\exp s^{2}-1\right)^{1 / 2} .
\end{aligned}
$$

\section{Results and discussion}

$\mathrm{X}$-ray diffraction (XRD) and transmission electron microscopy (TEM) characterization

$X R D$

The X-ray diffraction patterns of the mother liquors (see Table 1) consist of several relatively broad peaks indicative of the $\beta-\mathrm{FeOOH}$ akaganeite (Cornell and Schwertmann 2003; Post et al. 2003) (Fig. 1). The diffraction pattern of dextran powder (not shown) consists of very broad peaks centered at $2 \theta \approx 18^{\circ}$ and much weaker peaks around $2 \theta \approx 40^{\circ}$, which suggests not a crystalline, but rather a glassy state. This means that, in contrast to the iron oxide core material, dextran itself does not imply the crystalline phase. We have observed (diffractograms not shown) that in the presence of high excess of dextran coating in the solution the main peaks from the crystalline core material were overwhelmed by very broad peaks from dextran (a similar situation occurs in the case of Fesucrose, see Fig. 1). In such case the information provided by XRD patterns is less reliable than that acquired by other methods. However, when a solution with a higher iron content is studied (see Fig. 1, Fedextran (S)), the diffractogram is comparable in quality to those of classical freeze-dried samples (Kilcoyne and Lawrence 1999). The most pronounced 
diffraction peak, corresponding to the (211) plane (diffraction angle $2 \theta=35.3^{\circ}$ ), was used with the Scherrer formula (Klug and Alexander 1974) for estimating the mean crystalline dimension of the studied compounds. The results are reported in Table 1. In both iron dextran (Fe-dextran(S) and Fedextran) samples the diffraction peak corresponding to the $(310)$ plane $\left(2 \theta=26.7^{\circ}\right)$ allowed to estimate the mean crystalline dimension related to this plane as well (about 3.8-3.9 nm). This means that nanoparticles of these samples are distorted from the ideal spherical shape, in agreement with reports of other authors (Knight et al. 1999; Kilcoyne and Lawrence 1999; Bashir et al. 2009). Note that the XRD patterns of the studied samples appear to have a weak peak at $2 \theta \approx 61.15^{\circ}$, which would indicate the presence of $\mathrm{Cl}^{-}$anions. This is consistent with the tunnelcontaining akaganeite structure (Kudasheva et al. 2004; Kilcoyne and Lawrence 1999; Post et al. 2003).

\section{TEM}

TEM micrographs of the studied suspensions are shown in Fig. 2. In this particular case, utilization of the dedicated software for automated particle size distribution analysis is not possible because the particles are crowded and overlaps. To gain information about their dimensions, the particles were manually identified and their size was determined from the number of pixels occupied in the image. At least 100 particles, in different areas of the image, has been subjected to the above analysis. This made possible to draw a histogram presenting particle size distribution. As shown in Fig. 2a, c, d in happened that the shape of particles was ellipsoidal. In these cases, sizes of major and minor ellipse semiaxis were determined, which are represented by two peaks in appropriate histograms (insets in Fig. 2). The average sizes of the nanoparticles of the studied compounds are specified in Table 1. Note that all the compounds (excluding Fe-sucrose) show also a broad spectrum of possible aggregation (dimmers, trimmers) with a rather low population of the aggregates. At present it cannot be excluded that the occurrence of "background" aggregates may result from the preparation of the sample for electron microscopy studies. Spindle-shaped particles with a size of $(4 \times 20 \mathrm{~nm})$, approximately, have been already observed in Fe-dextran (S) by Lazaro et al. (2003). The data in Table 1 show a good agreement between the TEM and XRD results concerning the size of the mineral core. These results are also in very good agreement with those obtained for Fe-sucrose by Kudasheva et al. (2004), and for Fe-dextran (S) by other authors (Funk et al. 2001; Kilcoyne and Gorisek 1998).
Fig. 1 X-ray diffractograms of iron oxyhydroxide polysaccharide suspension in mother liquor solution in a quartz glass capillary. The vertical bars indicate the position of the main diffraction peak of akaganeite as specified in JCPDS \# 34-1266

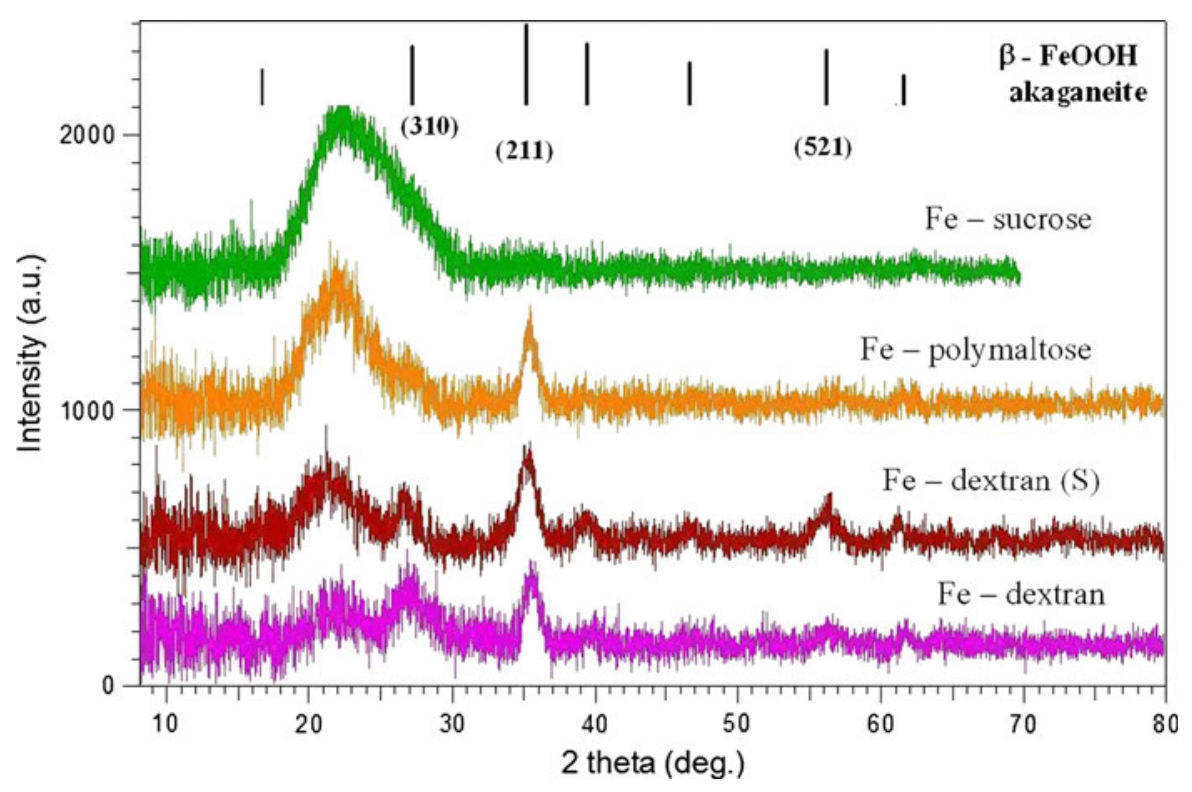




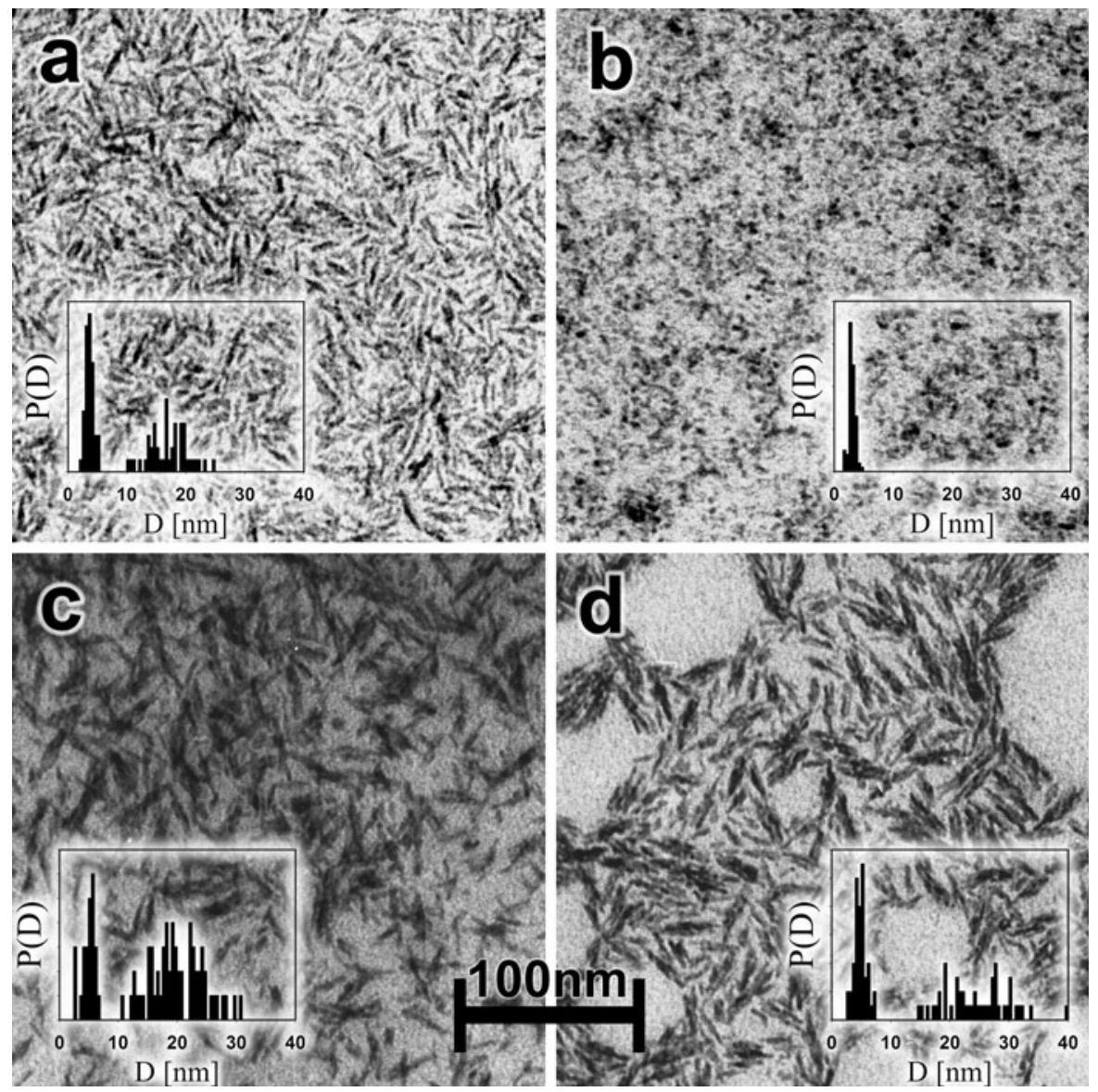

Fig. 2 TEM micrographs of aqueous suspension of iron oxyhydroxide polysaccharides: a Fe-dextran (S), b Fe-sucrose, c Fe-dextran, d Fe-polymaltose. The inset shows the distribution of nanoparticles size

Optical characterization

\section{Refractive index}

The refractive index measured for pure low molecular weight $(5 \mathrm{kDa})$ dextran and iron oxyhydroxide polysaccharide suspensions for several wavelengths in the range from 405 to $656 \mathrm{~nm}$ at room temperature (RT) shows a usual dispersion. The results can be easily described by a Sellmeier-type Equation (Daimon and Masumura 2007) allowing the calculation of the refractive index at $632.8 \mathrm{~nm}$, the wavelength used in the magnetic birefringence measurements (see Fig. 3; Table 1). In all the studied suspensions the index of refraction decreases monotonically with the temperature increasing to $313 \mathrm{~K}$ in a manner similar to that observed in pure water (see Fig. 3). Also the temperature dependence of the density (not shown) resembles that observed in pure water. The refractive index measurement data can be of use for estimating the polysaccharide concentration in the investigated samples. By assuming additional contributions of polysaccharide and akaganeite nanoparticles to the refractive index of the whole suspension we have established the concentration of sucrose and polymaltose equal to $340 \mathrm{~g} / \mathrm{L}$ and lower than $50 \mathrm{~g} / \mathrm{L}$, respectively, in these two suspensions. In the calculation we used the measured refractive index increment coefficient $\mathrm{d} n$ / $\mathrm{d} c$ equal to 0.103 and $0.133 \mathrm{~mL} / \mathrm{g}$ for pure sucrose $\left(\right.$ Ficoll ${ }^{\circledR}$ ) and maltose solutions, respectively. In the case of Fe-dextran (S) the polymer concentration in the mother liquor was $100 \mathrm{~g} / \mathrm{L}$, as specified by the supplier. The equal values of $n$ obtained for Fedextran and Fe-dextran (S) suggest similar polymer concentration in both solutions. 
Fig. 3 Refractive index dispersion for pure low molecular weight $(5 \mathrm{kDa})$ dextran and iron oxyhydroxide polysaccharide aqueous suspensions studied at room temperature

$\left(c^{\mathrm{Fe}}=c^{\mathrm{P}}=1 \mathrm{~g} / \mathrm{L}\right)$. The inset shows the temperature dependence of the refractive index for $\lambda=656.3 \mathrm{~nm}$. The wavelength and temperature dependences of $n$ for Fe-dextran and Fedextran (S) are identical within the error (the size of the error bar is smaller than the dimension of the experimental point)

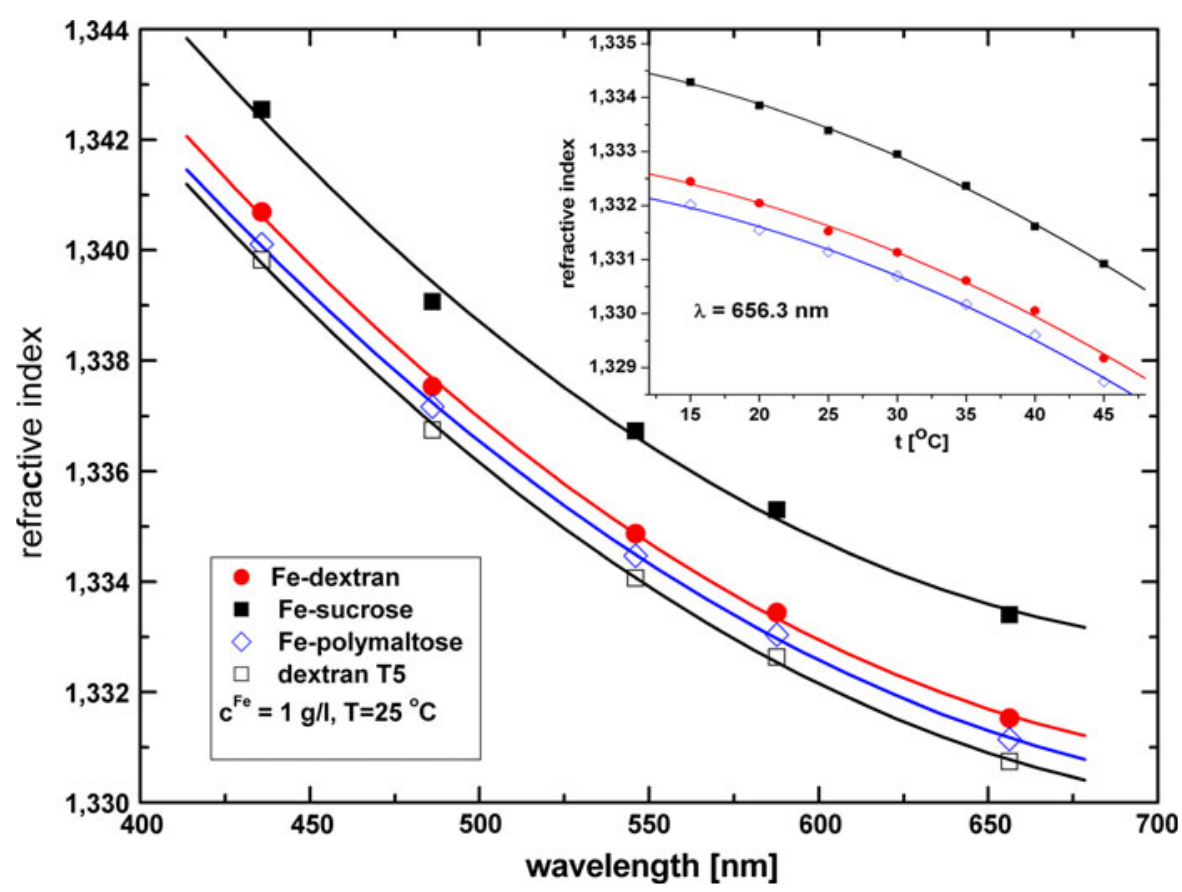

\section{UV-Vis absorption}

The electronic absorption spectra of the iron oxyhydroxide aqueous suspensions were studied in the spectral range from 200 to $900 \mathrm{~nm}$ in the temperature range from 280 to $362 \mathrm{~K}$. All the formulations exhibit a broad featureless absorption extending to the UV. The positions of the relevant bands are indicated by arrows in Fig. 4. The spectral dependence, similar in all the studied compounds, is analyzed in detail for $\mathrm{Fe}$ dextran (S) in Fig. 4.

The data obtained at RT for different iron concentration (from 50 to $0.04 \mathrm{~g} \mathrm{Fe} / \mathrm{L}$ ) and pathlength collapse very well into a single curve of the molar extinction coefficient, indicating no anomaly in the concentration dependence (see Fig. 4). Thus, at RT macroscopic aggregation can be judged not to occur and the complexes to be stable in the examined concentration range.

As an aid to the interpretation of the measured absorption we used a series of Gaussians fitted to the spectrum with the error function minimized with respect to the Gaussian height, width, and position. The results are shown in Fig. 4. In general, three groups of bands can by distinguished. The first group is composed of high-intensity bands below $200 \mathrm{~nm}$ related to transitions from optical chromophores of the polysaccharide shell (Matsuo and Gekko 2004). Only a part of one band can be seen here, with a maximum at about $187 \mathrm{~nm}$. The second group corresponds to oxometal charge transfer transitions of a relatively highintensity at 286 and $356 \mathrm{~nm}$. The third group includes low-intensity bands above $350 \mathrm{~nm}$ arising from a $d-$ $d$ transition of iron. Bands with a molar extinction coefficient of about $400 \mathrm{M}^{-1} \mathrm{~cm}^{-1}$ are seen to occur at 412 and $476 \mathrm{~nm}$, as well as three other very weak transitions (not used in the fitting procedure) at ca. 570,630 , and $900 \mathrm{~nm}$. The latter three only appear as a weak shoulder in solutions of very high concentration (see Fig. 4), with extinction coefficients as low as $10 \mathrm{M}^{-1} \mathrm{~cm}^{-1}$. The positions of the bands observed below $500 \mathrm{~nm}$ are in a good correlation with the reported spectra of other iron polysaccharide compounds, including iron-gluconate (Kudasheva et al. 2004) and iron-carrageenan (Jones et al. 2000). Also, very well-developed bands were found to occur at 650 and $900 \mathrm{~nm}$ for a $27-\mu \mathrm{m}$ thick crystal of goethite (http://minerals.gps.caltech.edu 2012).

The information acquired from the analysis of the absorption spectra allows to draw conclusions regarding the nature of the iron oxide core of the studied compounds. For low-spin Fe(III) the intensity of the $d-d$ transition bands should be higher than observed in our study. The presence of $\mathrm{Fe}(\mathrm{II})$ would result in a bands in the range from 420 to $450 \mathrm{~nm}$ and a highintensity band at 750 and $950 \mathrm{~nm}$ (Fontana et al. 
Fig. 4 Absorption spectra of Fe-dextran (S) at room temperature. Top, absorbance for different iron concentration and cell pathlength the values in nanometers indicate the positions of very weak bands. Middle, molar extinction coefficient expressed on the molar iron basis. Bottom, fitting of the molar extinction coefficient spectra (dashed line) to a Gaussian (solid line), with the best-fit Gaussian components indicated. The arrows indicate the position of maximum of individual bands obtained from the fit (the size of the error bar is smaller than the dimension of the experimental point)

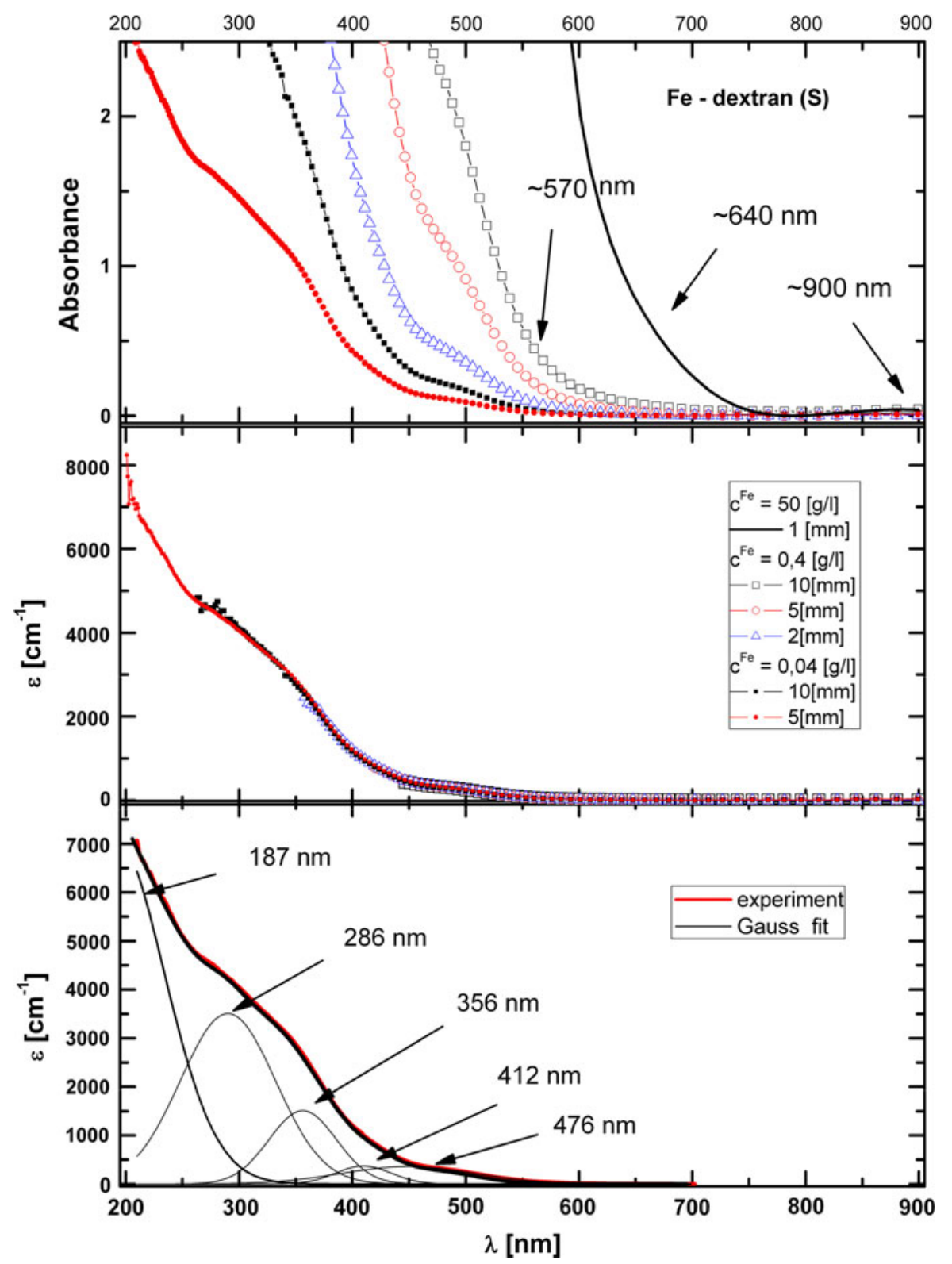

2007), which is not the case here, either (see Fig. 4). The observed low-intensity bands should be associated with characteristic $\mathrm{Fe}$ (III) bands in a high-spin state octahedrally coordinated to oxygen (Marusak et al. 1980; Fontana et al. 2007), which are compatible with the expected ferric oxyhydroxide mineral form.

A variable temperature UV-Vis optical absorption experiment was performed to determine the effect of the polysaccharide binding on the surface of akaganeite nanoparticles. To illustrate the change in the behavior as a result of heating, in Fig. 5 we present the temperature dependence of the absorption spectra of two of the studied samples, Fe-dextran (S) and Fepolymaltose. When heated to ca. $363 \mathrm{~K}$, Fe-polymaltose shows an absorption intensity reduced (by ca. $15 \%$ in the $350 \mathrm{~nm}$ band, see Fig. 5) with respect to the spectrum taken at $282.3 \mathrm{~K}$. The decrease in the absorption intensity with the temperature is more or less exponential, and the largest changes are observed in the bands below $400 \mathrm{~nm}$, ascribed to the oxo-metal charge transfer. This suggests a degradation of bonds between the core surface and the coating shell, which 
may affect the stability and the homogeneity of the suspension and lead to particle agglomeration. The core may be dismantled of the shell due to the low polysaccharide concentration in Fe-polymaltose in comparison to the other studied compounds. Therefore, this compound should not be stored much above room temperature. For Fe-dextran (S) and the other two compounds the changes in the absorption spectra upon heating to ca. $363 \mathrm{~K}$ are minor (below $2 \%$ in the $350 \mathrm{~nm}$ band, see Fig. 5). Any temperature-induced agglomeration is unlikely in these three compounds, which, therefore, are good models for further temperature magnetooptical studies.

\section{Magnetically-induced optical birefringence}

In all the aqueous suspensions of akaganeite nanoparticles we have studied the magnetically-induced optical birefringence $\Delta n$ versus the applied magnetic field of up to $2 \mathrm{~T}(20 \mathrm{kOe})$. Figure 6 shows a typical behavior of the measured $\Delta n$ for the iron concentration $c^{\mathrm{Fe}}=0.2 \mathrm{~g} / \mathrm{L}$. With the help of Eq. (4) and using the low magnetic field birefringence data (see the solid line in Fig. 6), we obtained the value of the Cotton-Mouton constant $C^{\mathrm{CM}}$ for each sample. Figure 7 shows concentration plots compared with the characteristics measured for commercial HSF. The specific $\mathrm{C}-\mathrm{M}$ constant values (i.e., $C^{\mathrm{CM}} / c^{\mathrm{Fe}}$ ) are listed in Table 2. The effect of the polysaccharide shell is seen to be negligible as the Cotton-Mouton constant measured in aqueous solutions of dextran is very small and only slightly depends on the concentration $\left(C^{\mathrm{CM}} \approx-(0.024 \pm 0.004) \times 10^{-14}\right.$ $\mathrm{mA}^{-2}$ ). The value of $C_{\mathrm{Ak}}^{C M}$ obtained for the examined akaganeite nanoparticle suspensions is relatively large (see Table 2), when compared with the values of the Cotton-Mouton constant measured in organic compounds (e.g., nitrobenzene, $C_{\mathrm{Nb}}^{C M}=3.32 \times 10^{-14}$ $\mathrm{mA}^{-2}$ (Battaglia and Ritchie 1977)) as well as that for horse spleen ferritin (see Table 2). It is, however, much lower than for aqueous suspension of nanoparticles of other iron minerals. For quite large goethite particles $\left(150 \times 25 \times 10 \mathrm{~nm}^{3}\right.$ nanorods) (Lemaire et al. 2004) the estimated value of $C_{\mathrm{Gt}}^{C M}$ is about $6.11 \times 10^{-10} \mathrm{~mA}^{-2}$ (for the same amount of iron, i.e., $1 \mathrm{~g} / \mathrm{L}$ ), whereas the magnetic moment per particle was found to be of ca. 1,100 $\mu_{\mathrm{B}}$. The values of the CottonMouton constant measured in magnetite (or maghemite) dispersions (Koralewski et al. 2011b, 2012b) were about five orders of magnitude higher than the $C_{\mathrm{Ak}}^{C M}$ values obtained in the present study. This recalls that in the studied akaganeite nanoparticles the contribution to the magnetic birefringence from the permanent magnetic moment should be relatively small.

The dependence of $C^{\mathrm{CM}}$ on the iron concentration is clearly linear in a very wide concentration range (more
Fig. 5 Temperature dependence of absorption spectra of Fe-polymaltose. Inset temperature dependence of absorption spectra of Fe-dextran (S); the arrow indicates the position of the isosbestic point

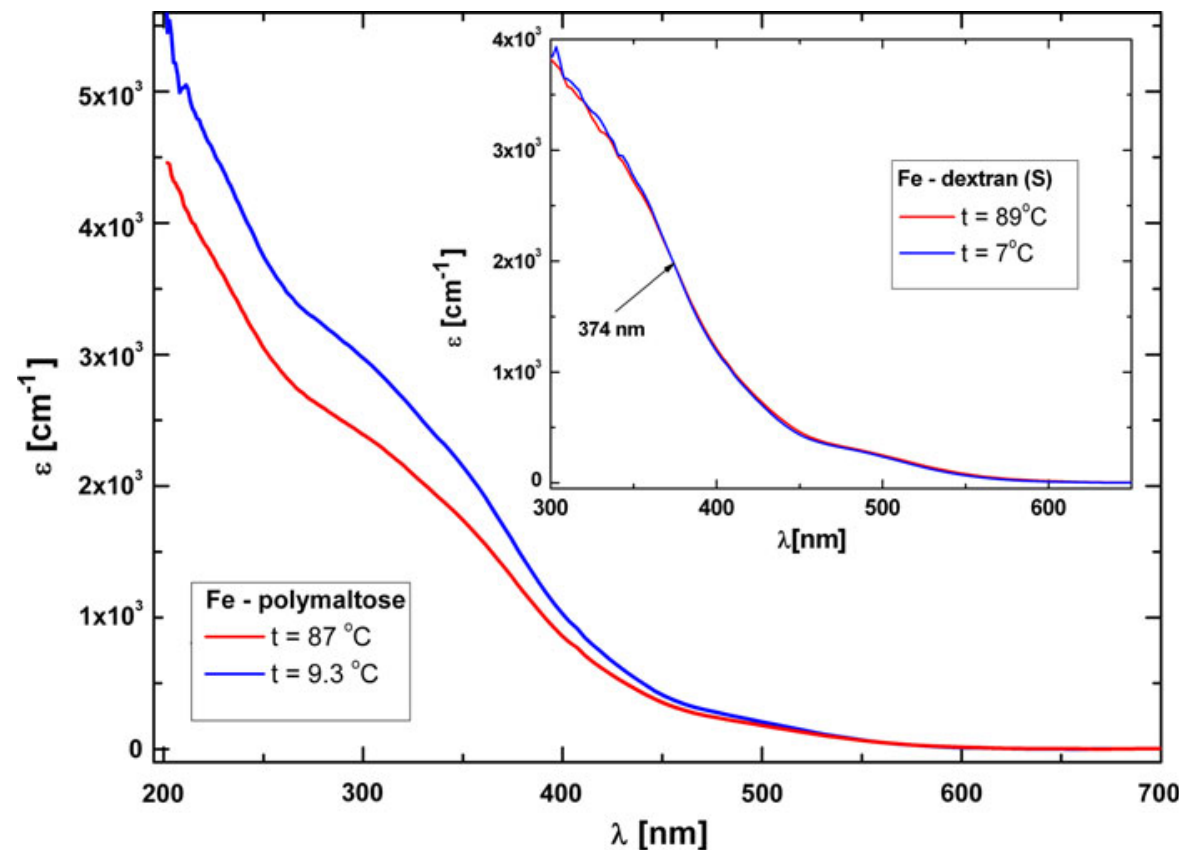


than five decades, see Fig. 7). This shows that the nanoparticles only interact magnetically with the external field. No inter-particle interaction occurs even at the highest concentration examined, which suggests a relatively small magnetic moment of the particles.

The results presented in Fig. 7 also indicate that the presence of ferritin (or its mimetics) in an unknown solution can be confirmed down to the relatively low iron concentrations of the order of $10^{-3}-10^{-4} \mathrm{~g} / \mathrm{L}$. The measurement sensitivity can be increased still further by two or three orders of magnitude by using a more precise polarimeter (see for example dual channel balanced photodetector system described by $\mathrm{Ku}$ et al. (2008) and performing the measurements in higher magnetic field, which nowadays may reach $11 \mathrm{~T}$ using commercial superconducting split magnets (for example see Oxford Instruments Spectromag system (http://www.oxford-instruments.com 2013)). This may open a possibility for detecting and tracking non-heme metaloproteins in serum or human body fluids. Thus, the linear relation between the $\mathrm{C}-\mathrm{M}$ constant and the iron concentration in a wide range, together with discrimination of mineral core provides a basis for possible analytical applications of the $\mathrm{C}-\mathrm{M}$ effect in biomedicine. It is important to note that recently rapid detection method for malaria diagnosis based on magnetooptical phenomena discussed here was presented and tested (Newman et al. 2008; Mens et al. 2010). Quite recently some further improvement in detection of malaria pigments based on magnetically-induced birefringence/dichroism measurements have been proposed lately (Butykai et al. 2012).

Only in the case of $\mathrm{Fe}$-sucrose the magnetic birefringence is seen to depart from the simple quadratic dependence, which indicates the beginning of the saturation process (Fig. 6). Therefore, solely for this sample we used a graphical method of estimation of the value of $\Delta n_{\mathrm{s}}$, described in "Theoretical background" section. The approximate $\Delta n_{\mathrm{s}}$ value (normalized to $1 \mathrm{~g} / \mathrm{L}$ iron concentration) obtained for $\mathrm{Fe}$ sucrose in this approach is about $7 \times 10^{-7}$. Assuming the akaganeite density (Cornell and Schwertmann 2003) and the particle size as specified in Table 1, we obtained the volume fraction and the volume concentration $\rho^{\mathrm{N}}$. Using these values and Eq. (2) we calculated the optical polarizability anisotropy per particle to obtain approximate value $\Delta \alpha=10 \times 10^{-40} \mathrm{Cm}^{2} \mathrm{~V}^{-1}$. On the assumption that this value is a material constant for akaganeite, the values for other iron oxyhydroxide polysaccharide suspensions were estimated from the relation
Fig. 6 Specific magnetic birefringence $\Delta n / c^{\mathrm{Fe}}$ versus the square of applied magnetic field for iron oxyhydroxide polysaccharide aqueous suspension (iron concentration $\left.c^{\mathrm{Fe}}=0.2 \mathrm{~g} / \mathrm{L}\right)$. The solid line indicates the low-field region; the dashed lines serve as eye guides. The vertical bar marks the error for experimental points (for clarity the error bar is marked for one point only)

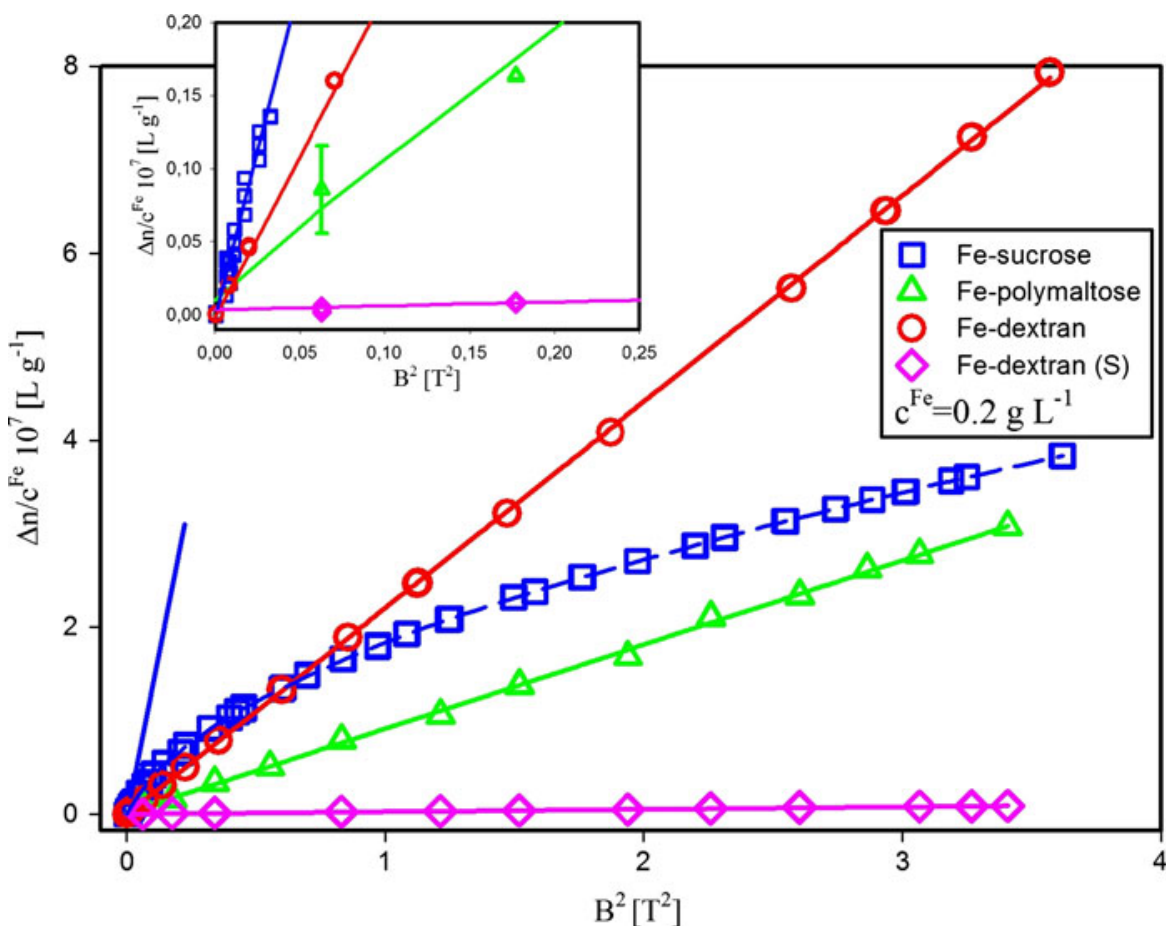


Fig. 7 Absolute value of Cotton-Mouton constant $C^{\mathrm{CM}}$ versus iron concentration for ferritin and iron polysaccharide aqueous suspensions (Ferritin ref.-data from Pankowska and Dobek 2009). The values of $C^{\mathrm{CM}}$ for dextran and bovine serum albumin (BSA) as well as for pure water are indicated, too. The size of the error bar is close to the dimension of the experimental point

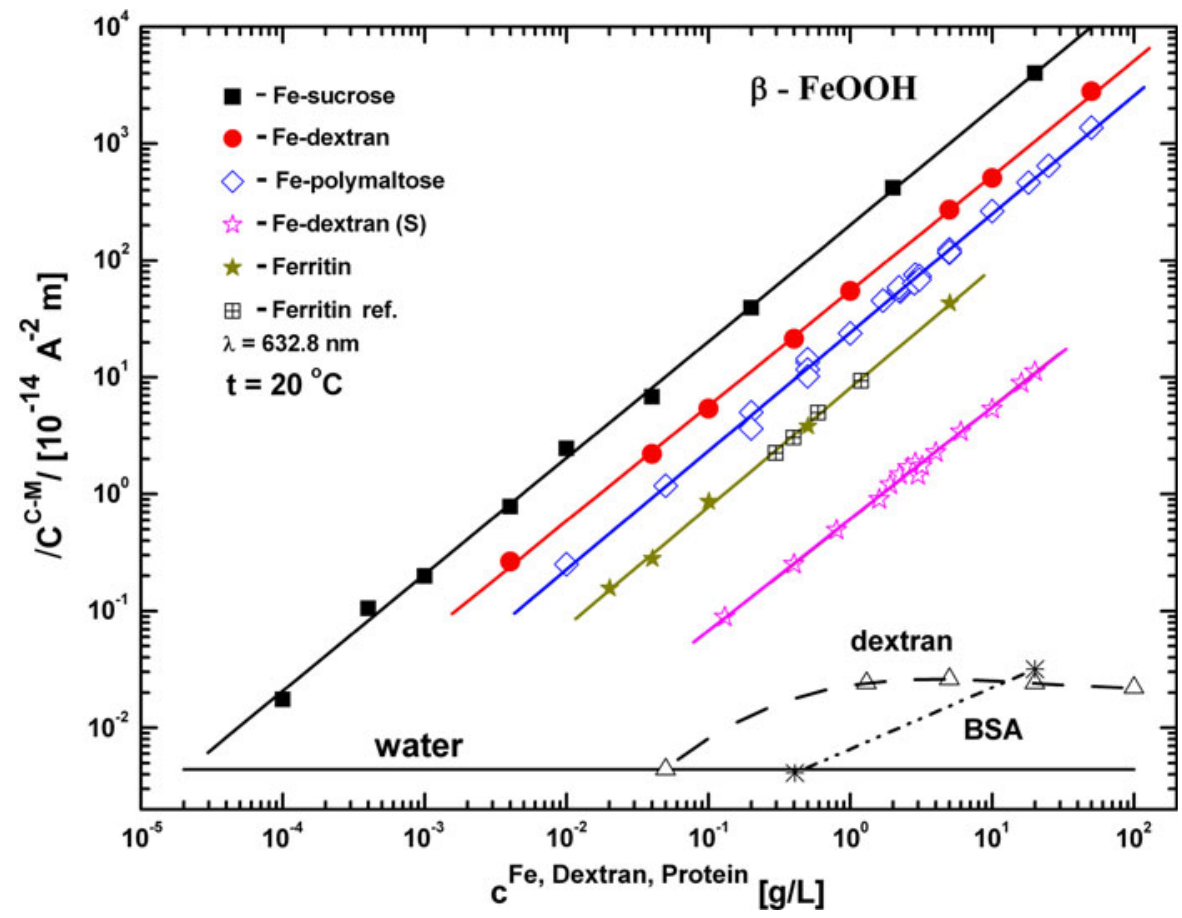

Table 2 Specific Cotton-Mouton constant, optical polarizability anisotropy, magnetic susceptibility anisotropy, magnetic moment, loading factor, and volume density of akaganeite nanoparticles and HSF, with error in parentheses

\begin{tabular}{llllll}
\hline Property & Fe-sucrose & Fe-polymaltose & Fe-dextran & Fe-dextran $(\mathrm{S})$ & Ferritin \\
\hline$C_{\mathrm{Sp}}^{\mathrm{CM}}\left(10^{-14} \mathrm{~mA}^{-2} \mathrm{Lg}^{-1}\right)$ & $203(3)$ & $24.4(0.5)$ & $55.1(1.4)$ & $0.62(0.02)$ & $8.1(0.4)^{\mathrm{e}}$ \\
$\Delta \alpha\left(10^{-40} \mathrm{Cm}^{2} \mathrm{~V}^{-1}\right)^{\mathrm{a}}$ & $10(3)$ & 80.1 & 45.3 & 282 & $5^{\mathrm{f}}$ \\
$\Delta \chi\left(10^{-20} \mathrm{JT}^{-2}\right)$ & $-6.1 / 6.4(0.6)^{\mathrm{d}}$ & - & $-4.6 / 4.8^{\mathrm{d}}$ & $-4.07 \times 10^{-2} / 4.24 \times 10^{-2 \mathrm{~d}}$ & $3.8^{\mathrm{f}}$ \\
$\mu_{\mathrm{m}}\left(\mu_{\mathrm{B}}\right)$ & $2,157 / 239^{\mathrm{d}}$ & - & $1,636 / 181^{\mathrm{d}}$ & $164 / 18^{\mathrm{d}}$ & $(128-556)^{\mathrm{g}}$ \\
$\mathrm{LF}^{\mathrm{b}}$ & 337 & 2,700 & 1,560 & 9,540 & 1,600 \\
$\rho^{\mathrm{N}}\left(10^{21} \mathrm{~m}^{-3}\right)^{\mathrm{c}}$ & 30.4 & 3.8 & 6.6 & 1.07 & $\sim 6$ \\
\hline
\end{tabular}

${ }^{a}$ The product $\Delta \alpha \Delta \chi$ for iron sucrose is negative; the sign of $\Delta \alpha$ was chosen arbitrarily

b Calculated for core diameter as in Table 1 (TEM)

c For $c^{\mathrm{Fe}}=1 \mathrm{~g} / \mathrm{L}$

${ }^{\mathrm{d}}$ For the second method of linearization, see text

e Specific Cotton-Mouton constant for apoferritin and ferritin with $\mathrm{LF}=2200$ is equal to $C_{\mathrm{sp}}^{\mathrm{CM}}=(0.018 \pm 0.004) \times 10^{-14} \mathrm{~mA}^{-2}$ and $C_{\mathrm{sp}}^{\mathrm{CM}}=(6.97 \pm 0.30) \times 10^{-14} \mathrm{~mA}^{-2}$, respectively

${ }^{\mathrm{f}}$ Data estimated from (Pankowska and Dobek 2009)

g Estimated from low-temperature magnetization measurements (Brem et al. 2006)

$(\Delta \alpha)^{\text {Fe-polysaccharide }}=(\mathrm{LF})^{\text {Fe-polysaccharide }} \times(\Delta \alpha)^{\text {Fe-sucrose }}$ 337, where LF is the number of Fe atoms per grain and 337 is LF for Fe-sucrose. The results are presented in Table 2 .

The induced magnetic birefringence was measured in different temperature conditions, and $C^{\mathrm{CM}}$ was calculated for each temperature. However, the Fepolymaltose sample was excluded from these measurements because of its low thermal stability. The results for the specific $C_{\mathrm{sp}}^{\mathrm{CM}}$ (i.e., $C^{\mathrm{CM}} / c^{\mathrm{Fe}}$ ) obtained for the other three PIC suspensions are shown in Fig. 8. The temperature dependence of the Cotton-Mouton 
constant is clearly nonlinear. The results were linearized (by the first method) by plotting the product $T C^{\mathrm{CM}}$ versus $1 / T$ (see Fig. 9), which allowed the determination of $\Delta \chi$ and $\mu_{\mathrm{m}}$ of the particle from the intercept and the slope of the linear dependence by using the estimate values of $\Delta \alpha$ (see Table 2). In the case of Fesucrose we were also able to estimate the saturation birefringence $\left(\Delta n_{\mathrm{s}}\right)$ for each measurement temperature (Fig. 10), and found that the temperature dependence of $\Delta \alpha$ was not negligible. In that case the second method of linearization yielded different values of $\Delta \chi$ and $\mu_{\mathrm{m}}$ (see Table 2), which describe well the magnetic properties of Fe-sucrose. It needs to be stressed that both linearization procedures are subject to relatively large error due to data collection, and can only be used in a relatively narrow temperature range far from $0 \mathrm{~K}$. The observation of full saturation birefringence in the other PIC samples would require very high magnetic fields (much higher than those used in this experiment). The estimate (see below) value of saturation magnetic field $B_{\mathrm{S}}$ is ca. $30 \mathrm{~T}$. Note that the highest magnetic field in which measurements of the C-M constant have been performed to date had a magnitude of ca. $20 \mathrm{~T}$ (Gielen et al. 2009). We hope that studies in stronger fields will be possible in the near future. At the moment, we can assume that for the other PIC compounds the temperature dependence of $\Delta n_{\mathrm{s}}$ is similar as for Fe-sucrose. The values of $\Delta \chi$ and $\mu_{\mathrm{m}}$ extracted on this assumption are specified in Table 2 . The $\Delta \chi$ values for akaganeite nanoparticles are of the same order of magnitude as those for HSF (see Table 2), but much higher than those for single organic molecules with a high anisotropy of magnetic susceptibility, such as benzene $(\Delta \chi \sim-1 \times$ $\left.10^{-27} \mathrm{JT}^{-2}\right)$ or porphyrin $\operatorname{ring}(\Delta \chi \sim-1 \times$ $10^{-26} \mathrm{JT}^{-2}$ ) (Maret and Dransfeld 1985).

The signs of saturation shown by the Fe-sucrose sample provided a basis for a tentative interpretation of the results in the Langevin formalism. The best fit to the experimental data by the Eq. (6a) (for a discrete particle diameter, i.e., monodisperse nano-ferrofluids) is obtained for the average magnetic moment of the particle $\mu_{\mathrm{m}} \approx 1,191 \mu_{\mathrm{B}}$ (see Table 4 , second column). This value is several times higher than that calculated by the second method of linearization; also the average diameter of the core is much higher in comparison to the XRD and TEM data. The quality of the fit is not very high, either. The TEM images (Fig. 2) indicate this could be related to the particle size distribution. Since the estimation of size of roughly spherical particles used in the magnetic measurements relies on Eq. (7), the saturation magnetization $M_{\mathrm{s}}$ of the material particle should be known. We attempted to calculate $M_{\mathrm{s}}$ from the available experimental magnetization data (Gutierrez et al. 2005) for Fe-sucrose.

The inset in Fig. 11 shows the magnetization $M$ plotted versus $B / k T$. The data for different values of $T$ collapse well into a single curve, suggestive of a temperature-independent $\mu_{\mathrm{m}}$. The experimental points have been fitted by the usual Langevin function $L_{1}(p)$ with $\mu_{\mathrm{m}}$ and $M_{\mathrm{s}}$ used as fitting parameters (see the inset in Fig. 11). The agreement is seen to be slightly better when the experimental magnetization $M$ is described by the sum of the Langevin function and a linear contribution to the magnetization, $\chi H$. Therefore, we have fitted also the expression: $M=M_{\mathrm{s}} L_{1}(p)+\chi H$. The fitting parameters are collected in Table 3. The value of $\chi$ obtained for Fesucrose akaganeite nanoparticles is of the same order as that reported for HSF (Zborowski et al. 1995; Makhlouf et al. 1997). The obtained value of $M_{\mathrm{s}}$, ranging from 11 to $13.9 \mathrm{Am}^{2} \mathrm{~kg}^{-1}$, seems rather high for the antiferromagnetic akaganeite. However, there are no other literature data for this particular material for comparison. We can compare this value with $M_{\mathrm{s}}=2.5 \mathrm{Am}^{2} \mathrm{~kg}^{-1}$ reported for $7 \mathrm{~nm}$ nanoparticles of a PIC compound marketed under the name Niferex (Mohie-Eldin et al. 1994). Slightly smaller (5 nm) ferrihydrite particles, pure or doped with $\mathrm{Ni}, \mathrm{Mo}$, and Ir, were found to have $M_{\mathrm{s}}$ in the range from 6 to 9 $\mathrm{Am}^{2} \mathrm{~kg}^{-1}$ (Punnoose et al. 2004). In this context, the relatively high value of $M_{\mathrm{s}}$ found for Fe-sucrose can be correlated with the very small diameter $(\sim 3 \mathrm{~nm})$ of the mineral core.

It is important to note here that the measured values of magnetization of Fe-dextran (S) (Gutierrez and Lazaro 2007) are more than 10 times lower than those of Fe-sucrose. At the same time the very weak departure from linearity of the experimental $M(B)$ dependence (Gutierrez and Lazaro 2007) clearly shows that saturation should be expected in very high magnetic field. The situation is similar to that observed for ferritin where full saturation of magnetization has not been observed even in the field as high as $55 \mathrm{~T}$ (Guertin et al. 2007; Silva et al. 2009). Thus, the average value of $\mu_{\mathrm{m}}$ for Fe-dextran (S) can be expected to be much smaller than that for Fe-sucrose. This 
Fig. 8 Temperature dependence of the specific Cotton-Mouton constant for iron oxyhydroxide polysaccharide aqueous suspensions with iron concentration $c^{\mathrm{Fe}}=0.04 \mathrm{~g} /$ $\mathrm{L}$. The values of $C^{\mathrm{CM}}$ for $\mathrm{Fe}$ dextran (S) have been magnified by the factor of 100. The vertical bar marks the error for experimental points

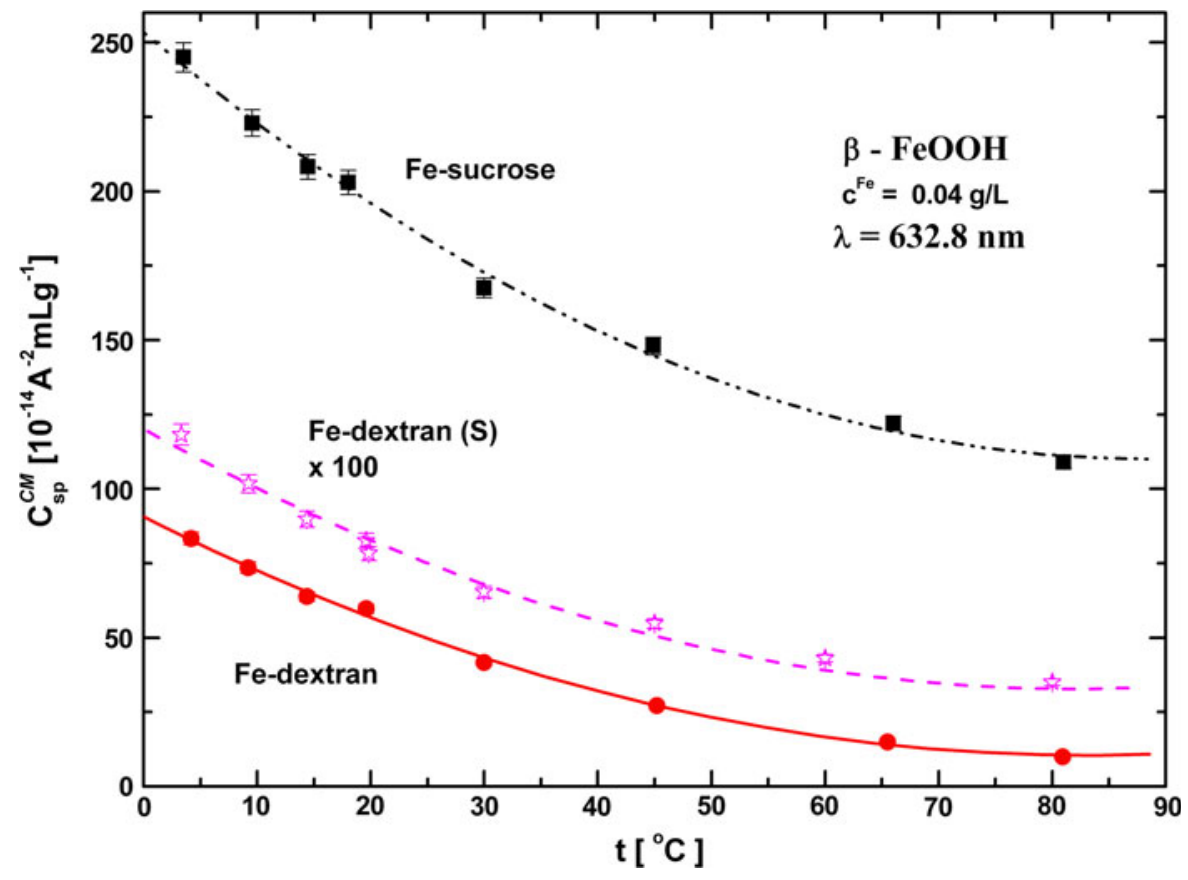

Fig. 9 Product $T C^{\mathrm{CM}}$ versus $1 / T$ for iron oxyhydroxide polysaccharide aqueous suspensions; the lines are the best fit by the linear equation. The vertical bar marks the error for experimental points

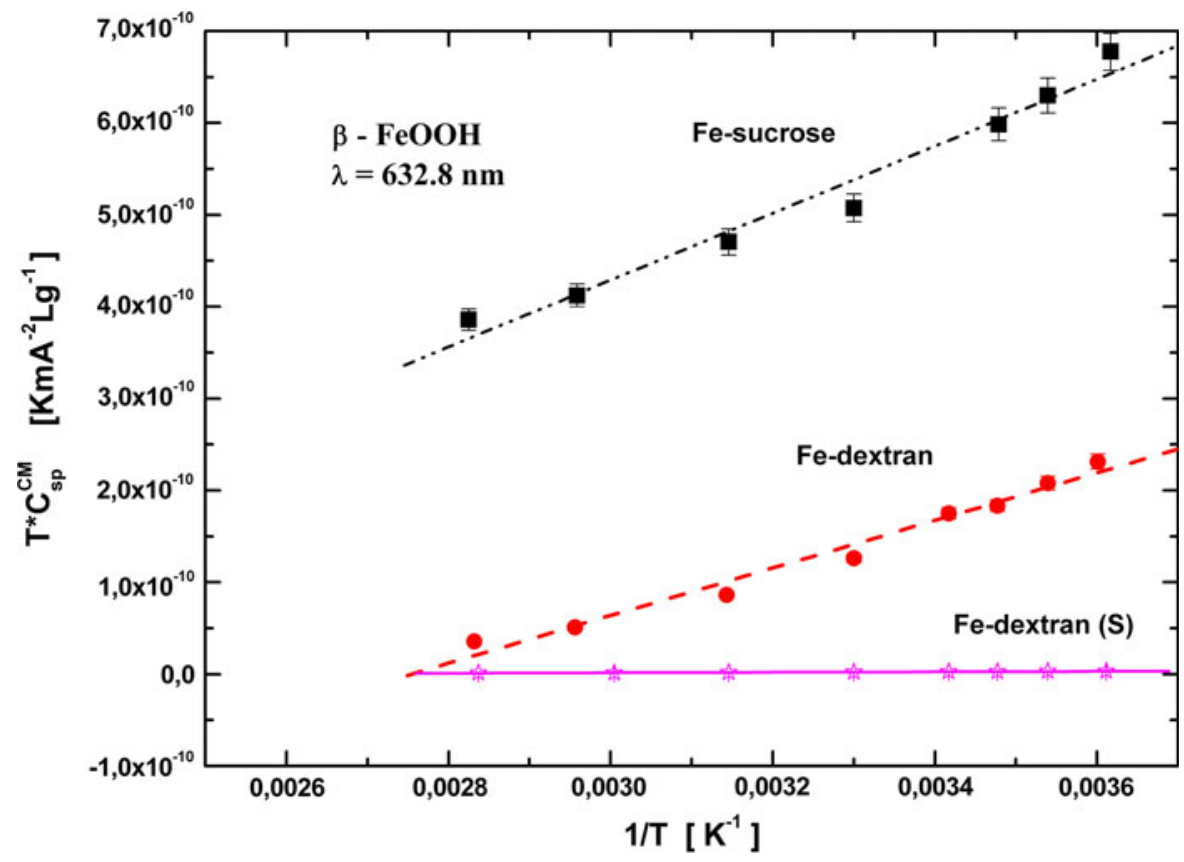

relation is in very good agreement with the estimated values of $\mu_{\mathrm{m}}$ specified in Table 2 .

The experimental values of magnetic birefringence of Fe-sucrose were fitted by the Langevin function described by the Eq. (6) and (6a) with a log-normal distribution (see Eq. (9)) and the assumed value of $M_{\mathrm{s}}=13.9 \mathrm{Am}^{2} \mathrm{~kg}^{-1}$. The effect of the $\Delta n_{\mathrm{s}}$ value on the goodness of fit with a specific Langevin function was tested, too. The respective values of fitting parameters are collected in Table 4 . The fits are seen to be better for $\Delta n_{\mathrm{s}}$ much higher $\left(\sim 20 \times 10^{-7}\right)$ than the value obtained by the graphical approximation method $\left(\sim 7 \times 10^{-7}\right)$. The obtained values of $\langle D\rangle$ and their distribution, shown in Fig. 11, are in good 
Fig. 10 Temperature dependence of the specific saturation magnetic birefringence $\Delta n_{\mathrm{s}}$ for the $\mathrm{Fe}$ sucrose aqueous suspension $\left(c^{\mathrm{Fe}}=0.04 \mathrm{~g} / \mathrm{L}\right.$,

$\lambda=632.8 \mathrm{~nm})$. In the inset, the product $G T C^{\mathrm{CM}}$ versus $1 / T$; the line is the best fit by the linear equation. The vertical bar marks the error for experimental points (for clarity the error bar is marked for one point only)
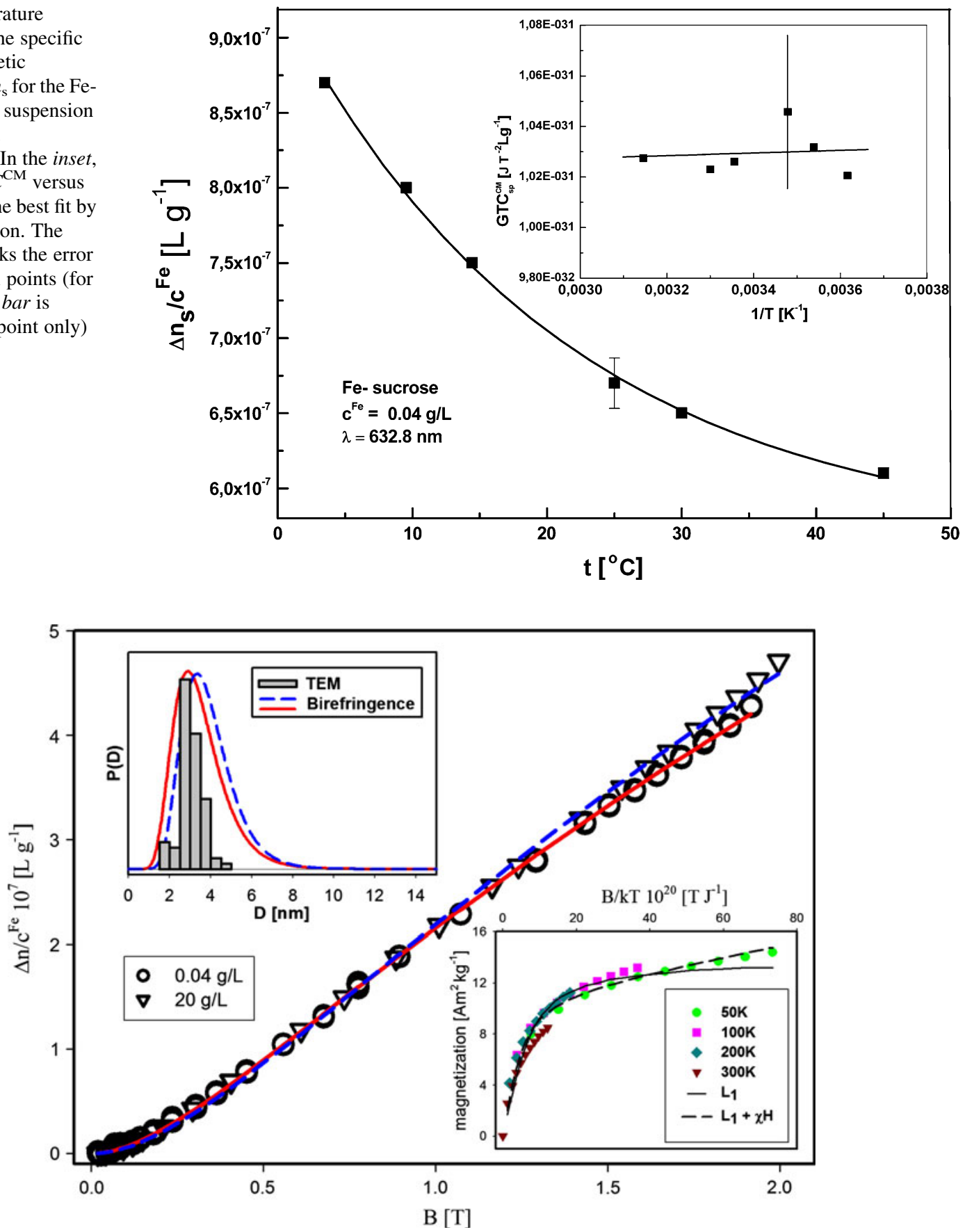

Fig. 11 Specific magnetic birefringence $\Delta n / c^{\mathrm{Fe}}$ as a function of the applied magnetic field for $\mathrm{Fe}$-sucrose aqueous suspension $\left(c^{\mathrm{Fe}}=0.04\right.$ and $\left.20 \mathrm{~g} / \mathrm{L}\right)$. The dashed and solid lines are the best fit by the Langevin function by Eqs. (6) and (9). Top inset particle size distribution obtained in TEM and magnetic birefringence measurements. Bottom inset magnetization versus
$B / k T$; the dashed and solid lines are the best fit to the experimental points (data from Gutierrez et al. 2005) by the usual Langevin function and the usual Langevin function plus the linear term $\chi H$, respectively. The size of the error bar is close to the dimension of the experimental point 
Table 3 The parameter values obtained in the fitting procedure with different types of function describing the magnetization for Fe-sucrose; $\chi^{2}$ describes the goodness of the fit

\begin{tabular}{lll}
\hline Type of function & $L_{1}(p)$ & $L_{1}(p)+\chi H$ \\
\hline$M_{\mathrm{s}}\left(\mathrm{Am}^{2} \mathrm{~kg}^{-1}\right)$ & 13.9 & 11.41 \\
$D(\mathrm{~nm})$ & 4.67 & 5.70 \\
$\mu_{\mathrm{m}}\left(\mu_{\mathrm{B}}\right)$ & 319 & 467 \\
$\chi\left(10^{-7} \mathrm{~m}^{3} \mathrm{~kg}^{-1}\right)$ & $\mathrm{na}$ & 0.151 \\
$\chi^{2}$ & 0.625 & 0.411 \\
\hline
\end{tabular}

na not applicable

agreement with the diameter obtained from XRD and TEM (see Table 4, columns 4 and 5, and Fig. 11). Also $\left\langle\mu_{\mathrm{m}}\right\rangle$ obtained for high $\Delta n_{\mathrm{s}}$ in the fitting procedure is in good agreement with the value resulting from the second method of linearization of the temperature dependence of the $\mathrm{C}-\mathrm{M}$ constant (see Tables 2, 4).

In the estimation based on the best-fit parameters (see Table 4, column 4) the magnitude of the magnetic field corresponding to $80 \%$ of birefringence saturation is found to be of ca. $30 \mathrm{~T}$. This means that any future validation of the values of magnetic characteristics of Fe-sucrose obtained in isothermal experiment will require fields of magnitude as high as 20-30 T. This is not a simple task, though. Alternatively, we have shown that good information on the anisotropy of susceptibility and the magnetic moment of the studied compounds can be obtained from temperature measurements with a field of the order of only a few Tesla's.

Table 4 The parameter values obtained in the fitting procedure with different types of Langevin function for Fe-sucrose $\left(M_{\mathrm{s}}=13.9 \mathrm{Am}^{2} \mathrm{~kg}^{-1}\right)$, with average magnetic moment $\left\langle\mu_{\mathrm{m}}\right\rangle$, average diameter $\langle D\rangle$, its standard deviation $\sigma$ and the coefficient $R^{2}$ or $\chi^{2}$ describing the goodness of the fit

\begin{tabular}{llllll}
\hline Type of function & $L_{2}(p, q)$ & $L_{2}(p, q)$ & $L_{2}(p)$ & $L_{2}(p)$ & $L_{2}(p, q)$ \\
\hline$\Delta n_{\mathrm{s}}\left(10^{-7}\right)^{\mathrm{a}}$ & 7 & 7.34 & 7 & 20 & 20 \\
$D_{0}(\mathrm{~nm})$ & 6.2 & na & 7.52 & 3.28 & 2.95 \\
$s$ & 0.24 & na & 0.0012 & 0.35 & 0.69 \\
$\langle D\rangle(\mathrm{nm})$ & 6.4 & 7.24 & 7.52 & 3.49 & 3.74 \\
$\sigma(\mathrm{nm})$ & 1.56 & na & 0.1 & 1.28 & 2.92 \\
$\left\langle\mu_{\mathrm{m}}\right\rangle\left(\mu_{\mathrm{B}}\right)$ & 823 & 1,191 & 1,135 & 133 & 159 \\
$\Delta \chi\left(10^{-21} \mathrm{JT}^{-2}\right)$ & 6.21 & 0.62 & na & na & 4.56 \\
$R^{2} / \chi^{2}$ & 0.9988 & 0.9981 & 1.262 & 0.103 & 0.9995 \\
\hline
\end{tabular}

na not applicable

${ }^{\mathrm{a}}$ At RT and $\lambda=632.8 \mathrm{~nm}$, for $c^{\mathrm{Fe}}=1 \mathrm{~g} / \mathrm{L}$
In the mineral core of Fe-sucrose the estimated magnetic moment per particle was found to be about 133-239 $\mu_{\mathrm{B}}$, depending on the analysis method used. These values are similar to those reported in the literature for HSF (Kilcoyne and Cywinski 1995; Brem et al. 2006) (see Table 2). Although bulk akaganeite, being an antiferromagnet below room temperature, should not possess bulk magnetization, also magnetic properties are known to strongly depend on the particle size. In fact, HSF and the studied akaganeite suspension show superparamagnetic properties, as observed by the VSM method. (Neel 1961) showed that very small antiferromagnetic particles do exhibit a net magnetic moment resulting from incomplete surface spin compensation. The effect occurs when the surface spins outnumber the volume ones. This surface-to-volume effect is seen well in the compound studied: the estimated $\mu_{\mathrm{m}}$ decreases with increasing size of the nanoparticles (see Tables 1,2). For fine nanoparticles with a diameter below $\sim 5 \mathrm{~nm}$ the number $N_{\mathrm{u}}$ of uncompensated spins is of the order of $\left(N_{\mathrm{p}}\right)^{1 / 2}$, where $N_{\mathrm{p}}$ is the number of magnetic ion spins per particle (Neel 1961). Assuming the theoretical value of magnetic moment of $\mathrm{Fe}^{3+}$ equal to $5.92 \mu_{\mathrm{B}}$, from this relation we get the value of magnetic moment per particle of ca. $110 \mu_{\mathrm{B}}$ for Fe-sucrose, which is in quite good agreement with the experimentally obtained value of $133 \mu_{\mathrm{B}}$.

Using Eq. (5) and the values of $\Delta \chi$ and $\mu_{\mathrm{m}}$ we can compare their relative contributions to the measured value of $C_{\mathrm{sp}}^{\mathrm{CM}}$. For Fe-sucrose the contribution $\Delta C_{\Delta \chi}$ from the magnetic susceptibility anisotropy is ca. 60 times higher than the contribution $\Delta C_{\mu \mathrm{m}}$ from the permanent magnetic moment of the nanoparticle, i.e., $\Delta C_{\Delta \chi} \gg \Delta C_{\mu \mathrm{m}}$. With the actual nanoparticle size used in the Eq. (5) (particle volume fraction $\phi=\rho^{\mathrm{N}} V$ and $\mu_{\mathrm{m}}=M_{\mathrm{s}} V$ ) we can distinguish two general relations describing the $\mathrm{C}-\mathrm{M}$ constant for spheroid particles with low eccentricity, in which case the particle volume can be approximated by $V=\pi D^{3} / 6$. One relation is $C^{\mathrm{CM}} \propto$ $1 / D^{3}$, and applies to $\Delta C_{\Delta \chi} \gg \Delta C_{\mu \mathrm{m}}$. The other one is $C^{\mathrm{CM}} \propto D^{3}$, and corresponds to the opposite situation, i.e., $\Delta C_{\mu \mathrm{m}} \gg \Delta C_{\Delta \chi}$. Of course, in the case of nanoparticles in the form of a disk or a rod the relation between $C^{\mathrm{CM}}$ and the main dimensions of the particle will be different. The studied nanoparticle suspensions are found to fulfill the relation $C^{\mathrm{CM}} \propto 1 / D^{3}$ (see Fig. 12), which is consistent with the antiferromagnetic properties of HSF and akaganeite nanoparticles (Cornell and Schwertmann 2003). 
Fig. 12 Specific CottonMouton constant versus the number of $\mathrm{Fe}$ atoms per grain of iron oxyhydroxide polysaccharides and LF of ferritin (ref. data from Pankowska and Dobek for reconstitution of HSF core). Inset $C^{\mathrm{CM}}$ versus the inverse cube of the nanoparticle diameter $(D=7 \mathrm{~nm}$ for HSF). The vertical bar marks the error for experimental points

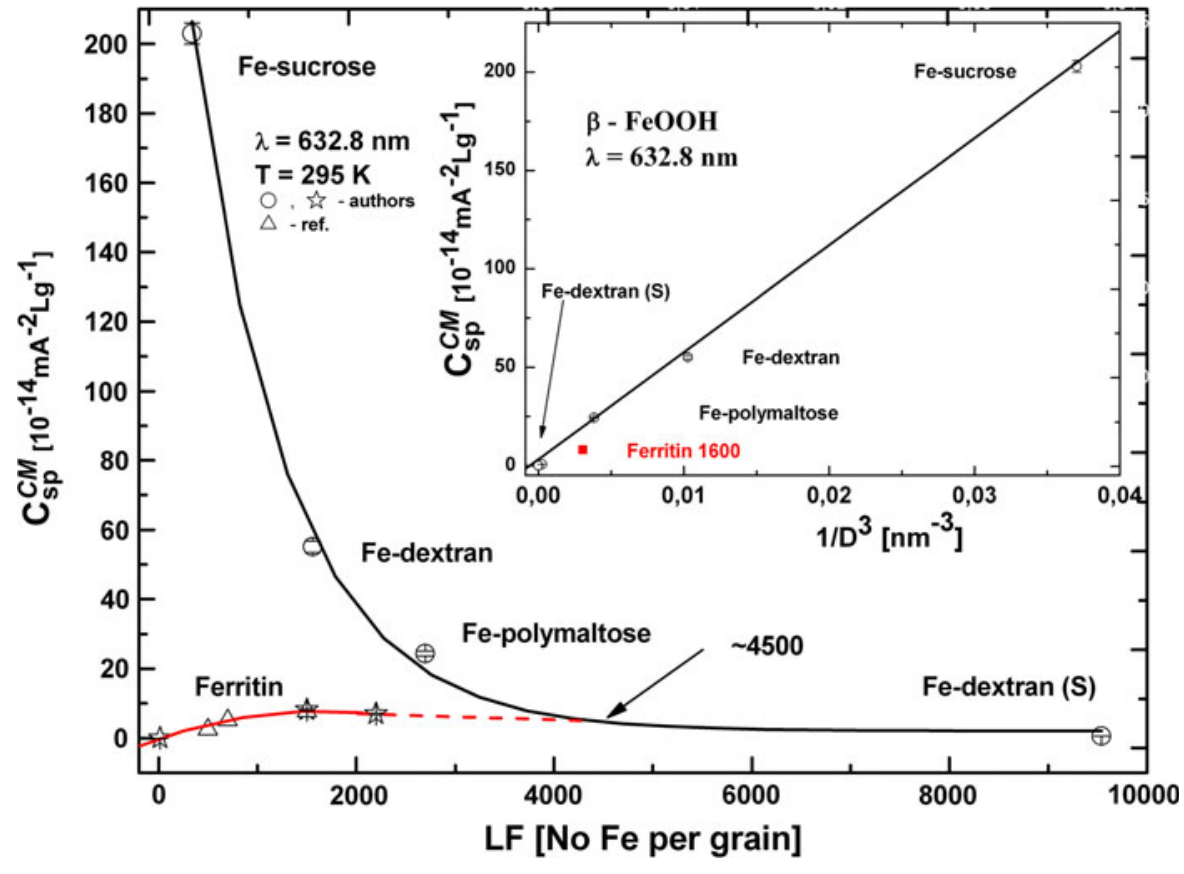

accordance with a more precise model of ferritin core very recently proposed by several authors (Pan et al. 2009; Ciasca et al. 2011). The electron microscopy study carried out by Pan et al. confirms that the mineral core of human hepatic ferritin is composed of surfacedisordered ferrihydrite subunits connected to a lowerdensity center. When the core is not fully loaded a reduction of density, or even a hole, in the center of the mineralized core can be expected to occur (Pan et al. 2009). A similar observation has been made on the basis of very recent small angle X-ray scattering (SAXS) measurements during iron release, used for modeling the cross-sectional shape of ferritin as a function of the metal content (Ciasca et al. 2011). Ciasca et al. suggest that the mineralization process starts from the shell and proceeds toward the center of the cavity. As the metal content increases the hole radius diminishes to vanish completely in the end. Also worthy of notice is the recent experimental observation of a hollow geometrical structure of the artificial $\mathrm{Co}_{3} \mathrm{O}_{4}$ ferritin (Kim et al. 2005).

\section{Conclusions}

The present paper is the first to report measurements of magnetic birefringence and its temperature dependence for akaganeite nanoparticles coated by a 
polysaccharide aqueous suspension (PIC). The measurement results are compared with the respective data we have obtained for horse spleen ferritin. We have also discussed the structural and magnetic properties studied by XRD, TEM, and VSM. The temperature dependence of the refractive properties as well as the UV-Vis absorption spectra provide further information on the stability of the formulation and the composition of the mineral core. The values of optical polarizability anisotropy and magnetic susceptibility anisotropy have been obtained from the temperature dependence of the saturation magnetic birefringence and the Cotton-Mouton constant, respectively. In the Fe-sucrose sample, the suspension with the smallest akaganeite nanoparticles, the isothermal dependence of the magnetic birefringence on the magnetic field has been described tentatively by different types of Langevin function to provide another way of estimation of the $\Delta \chi$ and $\mu_{\mathrm{m}}$ values. The net magnetic moment per particle has been found to be relatively small and to increase with decreasing grain diameter. This surface-to-volume effect observed for the studied compounds is consistent with the superparamagnetic behavior of the antiferromagnetic nanoparticles. The established relation between the $\mathrm{C}-\mathrm{M}$ constant and the diameter of the nanoparticles confirms the dominant contribution of the magnetic susceptibility anisotropy $\Delta \chi$ to the net magnetic birefringence of the studied compounds. The PICs and HSF show consistency in the magnetic behavior, which means that the studied hematinic formulations can be used as mimetic models of ferritin. The results provide evidence that the ferritin core has a structure of a non-Euclidian solid, which corroborates latest literature reports. Although the elucidation of the mineralization and demineralization processes requires further studies, these findings may be of help in the investigation of the possible role of ferritin in some diseases. The presented results show that magnetic birefringence/Cotton-Mouton effect measurements can provide an important tool for recognizing the magnetic properties of biologically relevant substances.

Acknowledgments We gratefully acknowledge the help of Dr. A. Szlaferek (PAS, Poznań), who performed the VSM measurements, and Dr. H. Gundelach (Schott AG), who presented us with a new refractometer prism. M. K. kindly thanks Professor Grzegorz Kamieniarz for helpful discussion, Dr. Maciej Krawczyk and Dr. Jarosław W. Kłos for comments on the manuscript, American Regent Inc. (Shirley, New York,
USA) for providing Dexferrum ${ }^{\circledR}$, and Pharmacosmos (Denmark) for providing dextran. This study has received support from the Polish Ministry of Science and Higher Education under Grant No. N N202 124535.

Open Access This article is distributed under the terms of the Creative Commons Attribution License which permits any use, distribution, and reproduction in any medium, provided the original author(s) and the source are credited.

\section{References}

Bashir S, McCabe RW, Boxall C, Leaver MS, Mobbs D (2009) Synthesis of $\alpha$ - and $\beta$-FeOOH iron oxide nanoparticles in non-ionic surfactant medium. J Nanopart Res 11:701-706

Battaglia MR, Ritchie GLD (1977) Molecular magnetic anisotropies from the Cotton-Mouton effect. J Chem Soc Far Trans 73:209-227

Brem F, Stamm G, Hirt AA (2006) Modeling the magnetic behavior of horse spleen ferritin with a two-phase core structure. J Appl Phys 99:123906

Butykai A, Orban A, Kocsis V, Szaller D, Bordacs S, TatraiSzekeres E, Kiss L F, Bota A, Vertessy B G, Zelles T, Kezsmarki I (2012) Malaria pigment crystals as magnetic micro-rotors: key for high-sensitivity diagnosis. arXiv: $1210.5920 \mathrm{v} 1$

Carneiro AAO, Fernandes JP, de Araujo DB, Elias J Jr, Martinelli ALC, Covas DT, Zago MA, Ângulo IL, Pierre TG, St. Baffa O (2005) Liver iron concentration evaluated by two magnetic methods: magnetic resonance imaging and magnetic susceptometry. Magn Res Med 54:122-128

Ciasca G, Chiarpotto M, Campi G, Bocca B, Rodio M, Pino A, Ricci A, Poccia N, Rossi C, Alimonti A, Amenitsch H, De sole P, Bianconi A (2011) Reconstitution of aluminium and iron core in horse spleen apoferritin. J Nanoprt Res 13:6149-6155

Coe EM, Bereman RD, Monte WT (1995a) An investigation into the size of an iron dextran complex. J Inorg Biochem 60:149-153

Coe EM, Bowen LH, Bereman RD, Speer JA, Monte WT, Scaggs L (1995b) A study of an iron dextran complex by Mössbauer spectroscopy and X-ray diffraction. J Inorg Biochem 57:63-71

Cornell RM, Schwertmann U (2003) The iron oxides. Wiley$\mathrm{UCH}$, Weinheim

Cotton A, Mouton H (1907) Sur les properiétés magnétooptiques des colloides et des liqueurs hétérogènes. Ann Chim Phys 11:145-203

Daimon M, Masumura A (2007) Measurement of the refractive index of distilled water from the near-infrared region to the ultraviolet region. Appl Opt 46:3811-3820

Dexferrum $^{\circledR}$ (2010) (iron dextran injection, usp) package insert. American Regent Inc., Shirley

Ferrum LEK ${ }^{\circledR}$ (2010) (ferri hydroxydum polymalthosum) package insert. LEK Pharmaceutical and Chemical Company, Slovenia

Fontana I, Lauria A, Spinolo G (2007) Optical absorption spectra of $\mathrm{Fe}^{2+}$ and $\mathrm{Fe}^{3+}$ in aqueous solution and hydrated crystals. Phys Stat Sol b224:4669-4677 
Frankel RB, Papaefthymiou GC, Watt GD (1991) Variation of superparamagnetic properties with iron loading in mammalian ferritin. Hyperfine Interact 66:71-82

Funk F, Long GJ, Hautot D, Buchi R, Christl J, Weidler PG (2001) Physical and chemical characterization of therapeutic iron containing materials: a study of several superparamagnetic drug formulations with the $\beta-\mathrm{FeOOH}$ or ferrihydrite structure. Hyperfine Interact 136:73-95

Gielen JC, Heyen AV, Klyatskaya S, Vanderlinden W, Höger S, Maan JC, De Feyter S, Christianen PCM (2009) Aggregation kinetics of macrocycles detected by magnetic birefringence. J Am Chem Soc 131:14134-14135

Guertin P, Harrison N, Zhou ZX, McCall S, Drymiotis F (2007) Very high field magnetization and AC susceptibility of native horse spleen ferritin. J Magn Magn Mater 308:97-100

Gutierrez L, Lazaro FJ (2007) Comparative study of iron-containing haematinics from the point of view of their magnetic properties. J Mag Mag Mater 316:136-139

Gutierrez L, del Puerto Morales M, Lazaro FJ (2005) Magnetostructural study of iron sucrose. J Magn Magn Mater 293:69-74

Harris JGE, Grimaldi JE, Awschalom DD, Chiolero A, Loss D (1999) Excess spin the dynamics of antiferromagnetic ferritin. Phys Rev B60:3451-3454

Harrison PM, Arosio P (1996) The ferritins: molecular properties, iron storage function and cellular regulation. Biochim Biophys Acta 1275:161-203

Hasmonay E, Dubois E, Bacri JC, Perzynski R, Raikher YuL, Stepanov VI (1989) Static magneto-optical birefringence of size-sorted $\gamma-\mathrm{Fe}_{2} \mathrm{O}_{3}$ nanoparticles. Eur Phys J B5:859-867

http://minerals.gps.caltech.edu/FILES/Visible/goethite/goethite. gif. Accessed Nov 2012

http://www.oxford-instruments.com/products/cryogenic-environ ments/superconducting-magnet-systems/wet-superconductingmagnets/magneto-optical-superconducting-magnet-system. Accessed June 2013

Ibrahim MM, Edwards G, Seehra MS, Ganguly B, Huffman GP (1994) Magnetism and spin dynamics of nanoscale $\mathrm{FeOOH}$ particles. J Appl Phys 75:5873-5875

Jones F, Cölfen H, Atonietti M (2000) Interaction of k-carrageenan with nickel, cobalt and iron hydroxides. Biomacromolecules 1:556-563

Kielich S (1970) Light scattering in solutions of rigid asymmetric biomacromolecules aligned in an electric or magnetic field. Acta Phys Polon A37:447-467

Kilcoyne H, Cywinski R (1995) Ferritin: a model superparamagnet. J Magn Magn Mater 140-144:1466-1467

Kilcoyne SH, Gorisek A (1998) Magnetic properties of iron dextran. J Magn Magn Mater 177-181:1457-1458

Kilcoyne SH, Lawrence JL (1999) The structure of iron dextran cores. Z Kristallogr 214:666-669

Kim JW, Choi SH, Lillehei PT, Chu SH, King GC, Watt GD (2005) Cobalt oxide hollow nanoparticles derived by biotemplating. Chem Commun 32:4101-4103

Klug HP, Alexander LE (1974) X-ray diffraction procedures for polycrystalline and amorphous materials. Wiley, New York

Knight B, Bowen LH, Bereman RD, Huang S (1999) Comparison of the core size distribution in iron dextran complexes using Mössbauer spectroscopy and X-ray diffraction. J Inorg Biochem 73:227-233
Kolbe F, Weiss H, Morgenstern P, Wennrich R, Lorenz W, Schruk K, Stanjek H, Daus B (2011) Sorption of aqueous antimony and arsenic species onto akaganeite. J Colloid Inter Sci 357:460-465

Koralewski M, Pochylski M, Gierszewski J (2011a) Magnetic birefringence of iron oxyhydroxide nanoparticles stabilised by sucrose. J. Magn. Magn. Mater 323:1140-1144 (Please note that the values of $\Delta \chi$ and $\mu_{\mathrm{m}}$ should be divided by $\mu_{\mathrm{o}}^{2}$ and $\mu_{\mathrm{o}}$ respectively)

Koralewski M, Pochylski M, Mitróová Z, Timko M, Kopcansky P, Melníková L (2011b) Magnetic birefringence of natural and synthetic ferritin. J Magn Magn Mater 323:2413-2417

Koralewski M, Kłos JW, Baranowski M, Mitróová Z, Kopčanský P, Melníková L, Okuda M, Schwarzacher W (2012a) The Faraday effect of natural and artificial ferritins. Nanotechnology 23:355704

Koralewski M, Pochylski M, Mitróová Z, Melníková L, Kováč J, Timko M, Kopčanský P (2012b) Magnetic birefringence study of the magnetic core structure of ferritin. Acta Phys Polon A 121:1237-1239

Ku BY, Chan M-L, Ma Z, Horsley DA (2008) Frequency-domain birefringence measurement of biological binding to magnetic nanoparticles. J Magn Magn Mater 320:2279-2283

Kudasheva DS, Lai J, Ulman A, Cowman MK (2004) Structure of carbohydrate-bound polynuclear iron oxyhydroxide nanoparticles in parenteral formulations. J Inorg Biochem 98:1757-1769

Lawrence R (1998) Development and comparison of iron dextran products. PDA J Pharm Sci Technol 52:190-197

Lazaro FJ, Larrea A, Abadia AR (2003) Magnetostructural study of iron dextran. J Mag Mag Mater 257:346-354

Lemaire BJ, Davidson P, Ferre J, Jamet JP, Petermann D, Panine P, Dozov I, Jolivet JP (2004) Physical properties of aqueous suspension of goethite $(\alpha-\mathrm{FeOOH})$ nanorods. Part I: in the isotropic phase. Eur Phys J E13:291-308

Lindley PF (1996) Iron in biology: a structural viewpoint. Rep Prog Phys 59:867-933

London E (2004) The molecular formula and proposed structure of the iron dextran complex, imferon. J Pharm Sci 93:1838-1846

Majorana Q (1902) Sur la birefringence magnetique. Compt Rend Acad Sci (Paris) 135:159-161

Makhlouf SA, Parker FT, Berkowitz AE (1997) Magnetic hysteresis anomalies in ferritin. Phys Rev B55:R14717R14720

Maret G, Dransfeld K (1985) Biomolecules and polymers in high steady magnetic fields. Topics Appl Phys 57:143-204

Marusak LA, Messier R, White WB (1980) Optical absorption spectrum of hematite, $\boldsymbol{\alpha}-\mathrm{Fe}_{2} \mathrm{O}_{3}$ near IR to UV. J Phys Chem Solids 41:981-984

Matsuo K, Gekko K (2004) Vacuum-ultraviolet circular dichroism study of saccharides by synchrotron radiation spectrophotometry. Carbohydr Res 339:591-597

Mens PF, Matelon RJ, Nour BYM, Newman DM, Schallig HDFH (2010) Laboratory evaluation on the sensitivity and specificity of a novel and rapid detection method for malaria diagnosis based on magneto-optical technology (MOT). Malaria J 9:207

Mohie-Eldin M-EY, Frankel RB, Gunther L (1994) A comparison of the magnetic properties of polysaccharide iron complex (PIC) and ferritin. J Mag Mag Mater 135:65-85 
Neel L (1961) Superparamagnétisme des grains trés fins antiferromagnétisme. Compt Rend Acad Sci (Paris) 252:40754080

Neitzel U, Barner K (1977) Optical measurements on ferromagnetic colloids. Phys Lett A 63:327-329

Newman DM, Heptinstall J, Matelon RJ, Savage L, Wears ML, Beddow J, Cox M, Schallig HD, Mens PF (2008) A magneto-optic route toward the in vivo diagnosis of malaria: preliminary results and preclinical trial data. Biophys $\mathbf{J}$ 95:994-1000

O’Konski CT, Yoshioka T, Orrtung WH (1952) Electric properties of macromolecules. IV. Determination of electric and optical parameters from saturation of electric birefringence in solutions. J Phys Chem 63:15581565

Oshtrakh MI, Milder OB, Semionkin VA (2006) Analysis of the iron state in ferric and ferrous iron containing pharmaceutical products by Mössbauer spectroscopy. J Radioanalyt Nucl Chem 269:547-553

Pan YH, Sader K, Powell JJ, Bleloch A, Gass M, Trinick J, Warley A, Li A, Brydson R, Brown A (2009) 3D morphology of the human hepatic ferritin mineral core: new evidence for a subunit structure revealed by single particle analysis of HAADF-STEM images. J Structur Biol 166:22-31

Pankowska M, Dobek A (2009) Linear and nonlinear magnetooptics of ferritin. J Chem Phys 131:015105

Peterlin A, Stuart HA (1939) Über die bestimmung der Größe und form, sowie der elektrischen, optischen und magnetischen anisotropie von submikroskopischen teilchen mit hilfe der künstlischen doppelbrechung und der inneren reibung. Z Phys 112:129-147
Popplewell J, Sakhnini L (1995) The dependence of the physical and magnetic properties of magnetic fluids on particie size. J Magn Magn Mater 149:72-78

Post JE, Heaney PJ, Van Drede RB, Hanson JC (2003) Neutron and temperature-resolved synchrotron X-ray powder diffraction study of akaganeite. Americ Mineral 88:782-788

Punnoose A, Phanthavady T, Seehra MS, Shah N, Huffman GP (2004) Magnetic properties of ferrihydrite nanoparticles doped with Ni, Mo, and Ir. Phys Rev B69:054425

Rasa M (2000) Magnetic properties and magneto-birefringence of magnetic fluids. Eur Phys J E 2:265-275

Schenck JF, Zimmerman A (2004) High-field magnetic resonance imaging of brain iron: birth of a biomarker? NMR Biomed 17:433-445

Scholten PC (1975) Magnetic measurements on particles in suspension. IEEE Trans Magn 11:1400-1402

Silva NJO, Millan A, Palacio F, Kampert E, Zeitler U, Rakoto H, Amaral VS (2009) Temperature dependence of antiferromagnetic susceptibility in ferritin. Phys Rev B 79:104405

Venofer $^{\circledR}$ (2009) Medical information booklet, (in Polish). LEK, Wroclaw

Venofer $^{\circledR}$ (2011) (iron sucrose injection) package insert. American Regent Inc., Shirley

Wilson SR, Ridler PJ, Jenings BR (1998) Magnetic birefringence of minerals. J Colloid Inter Sci 201:368-376

Xu C, Shi J, Zhou W, Gao B, Yue Q, Wang X (2012) Bromate romoval from aqueous solution by nano crystalline akaganeite $(\beta-\mathrm{FeOOH})$-coated quartz sand (CACQS). Chem Eng J 187:63-68

Zborowski M, Fuh ChB, Green R, Sun L, Chalmers JJ (1995) Analytical magnetapheresis of ferritin-labeled lymphocytes. Anal Chem 67:3702-3712 